\title{
Non-coding RNA gene families in the genomes of anopheline mosquitoes
}

\author{
Vicky Dritsou ${ }^{1 \dagger}$, Elena Deligianni ${ }^{2 \dagger}$, Emmanuel Dialynas ${ }^{2}$, James Allen ${ }^{5}$, Nikos Poulakakis ${ }^{3,4}$, Christos Louis ${ }^{1,2,3}$, \\ Dan Lawson ${ }^{5}$ and Pantelis Topalis ${ }^{2^{*}}$
}

\begin{abstract}
Background: Only a small fraction of the mosquito species of the genus Anopheles are able to transmit malaria, one of the biggest killer diseases of poverty, which is mostly prevalent in the tropics. This diversity has genetic, yet unknown, causes. In a further attempt to contribute to the elucidation of these variances, the international "Anopheles Genomes Cluster Consortium" project (a.k.a. "16 Anopheles genomes project") was established, aiming at a comprehensive genomic analysis of several anopheline species, most of which are malaria vectors. In the frame of the international consortium carrying out this project our team studied the genes encoding families of non-coding RNAs (ncRNAs), concentrating on four classes: microRNA (miRNA), ribosomal RNA (rRNA), small nuclear RNA (snRNA), and in particular small nucleolar RNA (snoRNA) and, finally, transfer RNA (tRNA).

Results: Our analysis was carried out using, exclusively, computational approaches, and evaluating both the primary NGS reads as well as the respective genome assemblies produced by the consortium and stored in VectorBase; moreover, the results of RNAseq surveys in cases in which these were available and meaningful were also accessed in order to obtain supplementary data, as were "pre-genomic era" sequence data stored in nucleic acid databases. The investigation included the identification and analysis, in most species studied, of ncRNA genes belonging to several families, as well as the analysis of the evolutionary relations of some of those genes in cross-comparisons to other members of the genus Anopheles.
\end{abstract}

Conclusions: Our study led to the identification of members of these gene families in the majority of twenty different anopheline taxa. A set of tools for the study of the evolution and molecular biology of important disease vectors has, thus, been obtained.

Keywords: Anopheles, Genome evolution, microRNA, ncRNA, Ribosomal genes, Small nuclear RNA, Small nucleolar RNA, tRNA, Whole Genome Sequencing

\section{Background}

Although it is a historic fact that control of malaria, as well as of most vector-borne diseases, has only been achieved through the control of the transmitting arthropod vectors, mosquito-related research has seriously lagged behind Plasmodium-related research for some time. It is only since the formation of the McArthur Foundation Network on Vector Biology [1] that a significant thrust was given to this study area. This increased research involvement soon led to the acquisition of the whole genome sequence of Anopheles gambiae [2], the

\footnotetext{
* Correspondence: topalis@imbb.forth.gr

${ }^{\dagger}$ Equal contributors

${ }^{2}$ Institute of Molecular Biology and Biotechnology, FORTH, Heraklion, Greece Full list of author information is available at the end of the article
}

most important African malaria vector; among insects, this was the second completed genome after that of Drosophila melanogaster [3]. The wealth of pertinent biological information available today for mosquitoes, combined with the tremendous increase of the power of genomics, has now made it easier to address projects that a few years ago would have been considered completely impractical. It was therefore natural that a consortium of more than 100 scientists was recently formed with the goal of sequencing and studying several genomic aspects of 16 anopheline species, many of which constitute important malaria vectors in several areas of the world [4]. In addition to obvious tasks such as genome assembly and general annotation, the project included the study of genes and gene families that were 
either important for the understanding of the vectors' biology, or that constituted target objects for inclusion in molecular approaches aiming at controlling disease transmission. The latter group included, for example, genes involved in chemosensation, detoxification and insecticide resistance, as well as genes whose products are found in the saliva of the mosquitoes, while the former included, among others, repetitive elements and noncoding RNA genes. Our team assumed responsibility for the study of the latter genes.

Several distinct RNA species have been detected during the last years in addition to the "classical" three RNA classes, mRNA [5,6], rRNA [7] and tRNA [8] that helped describe the central dogma of Molecular Biology established as such later [9]. The vast majority of those RNA species is known to not encode polypeptides; they are, therefore, collectively branded as non-coding RNAs or ncRNA [10]. The population of ncRNAs in any organism is made out of several distinct families of RNA species that are, usually, not related to each other, although the individual members of a given family, in addition to a common function, often share sequence and/or structure characteristics.

In the initial part of our involvement in the project, which we describe here, we chose to focus on four of these ncRNA families: the rRNA genes, including the chromosomally unlinked 5S rRNA genes, the small nucleolar RNA genes (snoRNA), the nuclear tRNA genes, and the miRNAs. Here we describe the analysis of these genes in their genomic context using a pure computational approach and expand this to include a study on the sequence evolution of the ribosomal genes. Although the "Anopheles Genomes Cluster Consortium", of which we are part, initially focused on the analysis of 16 different genomes, we expanded the study with the analysis of additional anopheline genomes for some gene families described here, due to their availability in the meantime. Therefore, in several cases we report the identification of ncRNA genes in up to 20 different genomes.

\section{Methods}

\section{Species and assemblies}

The assembled genomes of the following anopheline species were used in this analysis. For those taxa for which more than one assembly was available, the one used is indicated in parentheses following the name of the species: $A$. albimanus*, A. arabiensis*, A. atroparvus*, A. christyi, $A$. coluzzii, A. culicifacies, A. darlingi, A. dirus*, A. epiroticus, A. farauti* (AfarF1), A. funestus* (AfunF1), A. gambiae (AgamP4 and AgamS), A. maculatus, A. melas (AmelC1), A. merus" (AmerM1), A. minimus*, A. quadriannulatus*, A. sinensis* (AsinS1), A. stephensi* (AsteS1). RNAseq data [11] were used, when appropriate/available, for the species that are marked, above, with an asterisk. We note that a) some of these genomes ( $A$. darlingi and $A$. stephensi) were not part of the species originally chosen for the " 16 Anopheles genomes project" and b) for some ncRNA families some genomes did not yield any significant results, probably due to miss-assemblies, and are therefore excluded from the corresponding sections. Sequencing, assembly and annotation are described by [11]. All assemblies and sequences are publically available at VectorBase [12].

\section{Identification of rRNA genes}

To identify the ribosomal gene repeat, assemblies available through VectorBase were queried with different sequences using its BLAST [13] server. This was initially done using as queries, individually, the respective homologous D. melanogaster sequences encoding the 5.8S, $18 \mathrm{~S}$ and $28 \mathrm{~S}$ genes [14]. To potentially close gaps that were present in almost every repeat in all genomes analyzed, raw reads stored at the Sequence Read Archive/ SRA repository [15] were blasted using as queries, this time, the sequences previously identified with the BLAST searches performed for each species; contigs and consensus sequences were then manually assembled to the extent that this was possible. Finally, sequences present in Genbank were also compared to the sequences identified as above. In all cases in which Genbank contained ribosomal sequences for which we had not identified counterparts, those were retrieved and included in the output. The output should be considered a consensus sequence of the rDNA segment analyzed.

The same strategy used for the ribosomal repeat was also used for the isolation of the 5S rRNA gene, again starting with the D. melanogaster $5 \mathrm{~S}$ gene [16] as a query. BLAST searches of RNAseq experiments stored at the SRA repository were likewise used to determine the exact size of ribosomal transcripts for the $5 \mathrm{~S}$ genes where available.

\section{Phylogenetic analysis}

A total of 5.145 bp of concatenated DNA sequences (5S rRNA, 18S rRNA, 28SrRNA, mitochondrial 16SrRNA and COI) retrieved from 17 Anopheles species were phylogenetically analyzed (see Additional file 1). Drosophila melanogaster sequences [14] was used as an outgroup taxon.

DNA sequences were aligned using MAFFT v.6 [17] with auto (for COI) and Q-INS-i (for rRNA) strategies, removing ambiguous and poorly aligned regions. Each gene fragment was aligned separately. The best-fit model of DNA substitution was chosen for each gene fragment with jModelTest v. 2.1.5 [18], according to the Akaike Information Criteria (AIC). The analysis was run under 5 substitution schemes, base frequencies estimation $(+\mathrm{F})$, gamma shape $(+\mathrm{G})$ and invariable sites $(+\mathrm{I})$ estimation, which makes a total of 40 models. The models including both $\mathrm{G}$ and I were ignored [19]. The above parameters concluded 
in that K80, GTR + G, TrN + G, GTR + G, and GTR + G were the best fit models for the five fragments of genes (5S rRNA, 18S rRNA, 28SrRNA, 16SrRNA, and COI, respectively).

Bayesian Inference (BI), Maximum Likelihood (ML), and Neighbor-Joining analyses were conducted in MrBayes (v3.2.2) [20], RAxML (v. 7.2.7) [21] and MEGA (v. 6.0.6) [22], respectively. In all analyses nucleotides were used as discrete, unordered characters.

$\mathrm{BI}$ analysis was performed with four runs for $10^{7}$ generations and eight chains, using the K80, GTR + G, TrN + G GTR + G, and GTR + G models of evolution for $5 \mathrm{~S}$ rRNA, 18S rRNA, 28SrRNA, 16SrRNA, and COI, respectively, based on the results of the AIC. The current tree was saved to file every 100 generations. This generated an output of $10^{5}$ trees for every run. The performance of the runs was visualized using Tracer v1.6 [23]. The first $25^{*} 10^{3}$ trees $(25 \%)$ were discarded as "burn-in" and a majority rule consensus tree was calculated from the remaining trees. The posterior probabilities were calculated as the percentage of samples recovering a clade.

The ML analysis was performed under the GTRGAMMA model (General Time Reversible model of nucleotide substitution under the $\Gamma$ model of rate heterogeneity). To ensure that the inferred ML tree was not a local optimum $200 \mathrm{ML}$ searches for each dataset were conducted. The Robinson-Foulds symmetric distance was employed to assess the topological similarity between these trees [24]. The confidence of the branches of the best ML tree was further assessed based on 1000 rapid bootstrap replicates (under the GTRCAT model) (for more details see [21]).

\section{Identification of tRNA genes}

To identify tRNA genes in the assemblies of the different anopheline genomes we screened the assembled sequences with tRNAScan-SE [25]. To detect genes that potentially escaped the first search, we also used full genomic alignments of all scaffolds from all anophelines analyzed produced by Robert Waterhouse (MIT and University of Geneva) as input to the RNAZ 2.0 suite [26]. Any putative positive prediction was then BLASTed to the Rfam database $[27,28]$.

\section{Identification of miRNA genes}

For the identification of miRNAs a dual approach was chosen, $a b$ initio predictions and similarity searches. Two different pieces of software were used for $a b$ initio predictions, HHMMIR [29] and MiRPara [30]. Both treat genomic sequences as RNA molecules and predict their secondary structure. Next, they check the thermodynamic stability of those structures and they classify them as potential miRNA genes or not. HHMMIR and MiRPara differ in the classification algorithm, the first one using a Hidden Markov Model (HMM) whereas the second depends on a Support Vector Machine (SVM). A second difference is that HHMMIR was trained to predict (positive set) animal miRNA genes in general, while the positive set for MiRPara included miRNA genes from Anopheles gambiae, Aedes aegypti, Culex quinquefasciatus and Drosophila melanogaster, annotated as such in miRbase, v20 [31,32]. In both cases, each scaffold of every genome was analyzed separately in order to parallelize the process. Predictions with a confidence score lower than $80 \%$ were discarded. The remaining output (usually in the order of tens or hundreds of thousands) was kept for further filtering. The second computational strategy consisted of a similarity-based approach. Here, we used two ways to identify miRNA genes. The first consisted of querying, in BLAST searches, with known miRNAs from Aedes aegypti, Culex quinquefasciatus, A. gambiae and other invertebrate organisms stored at the corresponding section of RefSeq at NCBI, and present in the miRNA database miRBase v20. The second similarity scheme was to map, with zero mismatches allowed, to the anopheline genomic assemblies the mature miRNAs presently available in miRBase v20. The regions identified were then checked for the presence of miRNA genes by combining the mapping results with those of the other lines of evidence. Finally, we used the RNAz pipeline [26] to identify genomic regions in the assemblies that could contain non-coding RNA genes. We used genomic alignments for all the genomes available (kindly provided by Robert Waterhouse). Both MiRPara and HHMIR "chopped" every scaffold in segments of 521 bps in length with an overlap of 176 bps. Since RNAz analyzes alignments of a maximum of 6 sequences, multiple samples were taken and the presence of thermodynamically stable, non-coding RNAs was calculated. Any prediction with a confidence score lower than $90 \%$ was discarded. The presence of miRNA genes was then detected by BLASTing positive hits to the Rfam database. Rfam was last updated on August 2012; to potentially increase the number of putative miRNA genes, we BLASTed our hits versus the RefSeq-RNA database (downloaded 10 July 2014).

The results of the five lines of evidence were combined. miRNA genes predicted/identified by at least two different pipelines were considered to represent bona fide genes if the length of the predicted hit was greater than $70 \mathrm{bps}$. Also, since positive hits from genomic predictors or high scoring segments produced by BLAST usually do not start at the very same base, overlapping hits or hits that start within an area of 40 bps were considered as representing the same gene. Hits on opposite strands, even when in the same region, were kept in the final set. Several PERL scripts were written throughout this project. They were used as wrappers to facilitate the analysis of each scaffold separately in the local HPC cluster, or to combine, filter and compare the results compiling the final gene set. 


\section{Identification of small nucleolar RNAs (snoRNAs)}

Prediction of $\mathrm{C} / \mathrm{D}$ box snoRNAs was performed using snoScan [33]; candidate sequences returned with an initial score of $>20$ were retained. They were then examined "manually" and they were classified based on the computed possibility of the presence of a stem: no stem, possible stem, terminal stem and strong stem. SnoReport [34] was also used initially for an independent prediction of snoRNAs but, even using a probability score of pSVM >0.99, snoRNA genes were overpredicted, i.e. many more genes were predicted than what was expected from other organisms; SnoReport was, thus, not used further.

\section{Identification of small nuclear RNAs: snRNAs}

We used the RNAz pipeline [25] to identify genomic regions in the assemblies that contained genes putatively coding for snRNAs.

\section{Results and discussion The rDNA gene repeat}

Although among the very first genes to be isolated and described in metazoa (e.g. [35]), rRNA genes remain difficult study entities in the genomic era. Because genomes usually contain hundreds of copies of both the main rDNA repeat (that include the $5.8 \mathrm{~S}, 18 \mathrm{~S}$ and $28 \mathrm{~S}$ genes) and the small, unlinked $5 \mathrm{~S}$ rDNA repeats, their precise assembly is extremely tedious and, often, impossible. This is aggravated by polymorphisms, among others due to the frequent interruption of the genes in the main repeats by repetitive elements such as the ones found early on in D. melanogaster $([36,37])$ and other insects [38], including A. gambiae [39]; these insertions usually, but not exclusively, interrupt the $28 \mathrm{~S}$ gene. Finally, often more than one locus containing rDNA genes exist in a given genome, typically in both sex chromosomes. In A. gambiae, however, rDNA is found on the $X$ chromosome [40] although the possibility that some repeats are also localized on the Y chromosome cannot be excluded [41].

Examples of the difficulties encountered in the genomics of rDNA can be seen in the genome assemblies stored in VectorBase. The AfunF1 assembly of A. funestus, for example, only contains one $18 \mathrm{~S}$ and two $28 \mathrm{~S}$ genes, all in a segment of $\sim 50 \mathrm{~kb}$, arranged in a non-canonical way. Moreover, in addition to A. gambiae only 2 and 7 anopheline species contain annotations for the $28 \mathrm{~S}$ and $18 \mathrm{~S}$ ribosomal genes, respectively in VectorBase. Finally, although 14 anophelines are listed as containing (few) copies of the $5 \mathrm{~S}$ rRNA gene, these are wrongly annotated throughout as 5.8S RNA genes, though with shorter lengths. It should be noted that miss-annotations are not restricted to the assemblies in VectorBase. For example, the $3^{\prime}$ end of $5.8 \mathrm{~S}$ gene of $A$. atroparvus (Genbank accession \# AY050640) has been annotated to a nucleotide corresponding, in reality, to base pair \#97; it should be noted, though, that the sequence beyond this nucleotide contains several polymorphisms when compared to the one determined in the present study. As a result of this and other similar inconsistencies, we chose to initially disregard any previous annotations available, until we could verify them with the data acquired in the present analysis.

The results of the rDNA repeat analysis are summarized in Table 1, while all sequences identified the new anopheline assemblies [11] or database mining are reported in the Additional file 2.

\section{The 18S RNA genes}

In all organisms examined, the $18 \mathrm{~S}$ genes are the first of the ribosomal RNAs to be synthesized when Polymerase I initiates transcription at a promoter located at the end of the Non Transcribed Spacer (NTS, also called intergenic Spacer - IGS) of the rDNA repeat unit, giving rise to a large precursor RNA molecule that includes all rRNA species. This is then processed yielding the individual rRNA molecules. In $D$. melanogaster the primary transcript is led by a 864 nucleotides long segment called External Transcribed Spacer (ETS) [14], later to be "chopped off" during maturation. The summary of our analysis is presented in Table 1 and Additional file 2. While in the fruit fly the 18S rRNA is 1995 nucleotides long [14], we found that, in those species in which a complete $18 \mathrm{~S}$ gene was identified, its length ranges from $1786 \mathrm{bp}$ (A. epiroticus) to 2046 bp (A. farauti) (see Table 1). It should be noted, though, that we cannot ascertain that the $18 \mathrm{~S}$ sequences of A. epiroticus, A. sinensis and A. stephensi are complete, possibly missing a few bases at their $3^{\prime}$ end. By BLASTing the available SRA sequences and the assemblies present at VectorBase, as well as individual entries in Genbank, we managed to identify and assemble the complete $18 \mathrm{~S}$ rDNA sequences in 10 of the 17 anophelines analyzed (including the three aforementioned species). In 6 more species, only a partial assembly was achieved: at least $1000 \mathrm{bp}$ were identified in 4 taxa, but only $600 \mathrm{bp}$ in two of them. Finally, we were unable to identify unambiguously any of the $18 \mathrm{~S}$ sequences for A. culicifacies and $A$. melas using the available resources.

\section{The 5.8S RNA genes}

Insect 5.8S rRNAs, like their homologues in most living organisms, are encoded by a gene that is located in the ribosomal gene repeat between the $18 \mathrm{~S}$ and the $28 \mathrm{~S}$ genes [35] separating the long internal non-coding segment into the two internal transcribed spacers ITS1 and ITS2. An interesting feature of the $5.8 \mathrm{~S}$ gene in many insects [48] is the fact that it is split into two parts: a longer one of about $120 \mathrm{bp}$ in length, conventionally still called 5.8S, and a shorter $30 \mathrm{bp}$ long one named $2 \mathrm{~S}$ [49]. In $D$. melanogaster the latter is separated by a $28 \mathrm{bp}$ 
Table 1 The rDNA repeat in 17 anophelines

\begin{tabular}{|c|c|c|c|c|c|c|c|c|c|c|c|}
\hline Species & ETS “L” & ETS “S” & $18 \mathrm{~S}$ “L” & $18 \mathrm{~S}$ "S" & $18 \mathrm{~S}$ "C" & ITS1 “L” & ITS1 "S" & ITS1 “C” & $5.8 \mathrm{~S}$ & $5.8 S$ "S" & $5.8 \mathrm{~S}$ "C" \\
\hline Albimanus & 1538 & L78065 & 1977 & t.s. & Full & 242 & L78065 & Full & 160 & t.s. & Full \\
\hline Arabiensis & 0 & & 1981 & t.s. & Full & 346 & DQ287772 & Full & 160 & t.s. & Full \\
\hline Atroparvus & 0 & & 1965 & AM072973 [42] & Full & 0 & & & 144 & t.s. & part \\
\hline Christyi & 0 & & 583 & t.s. & Part & 0 & & & 155 & t.s. & Part \\
\hline Culicifacies & 0 & & 0 & & & 345 & EU244872 & Full & 160 & t.s. & Full \\
\hline Dirus & 0 & & 823 & AF417779 [43] & Part & 0 & & & 160 & t.s. & Full \\
\hline Epiroticus & 0 & & 1786 & t.s. & Full (?) & 0 & & & 160 & t.s. & Full \\
\hline Farauti & 0 & & 2046 & AF121054 [44] & Full & 1194 & EF042721 [15] & Full & 160 & t.s. & Full \\
\hline Funestus & 0 & & 1818 & t.s. & Full & 0 & & & 160 & t.s. & Full \\
\hline Gambiae & 0 & & 2015 & AM157179 [2] & Full & 344 & AAAB01006374 [5] & Full & 160 & t.s. & Full \\
\hline Maculatus & 0 & & 1950 & AF440198 & Full & 0 & & & 160 & t.s. & Full \\
\hline Melas & 0 & & 0 & & & 0 & & & 160 & t.s. & Full \\
\hline Merus & 0 & & 1518 & t.s. & Part & 0 & & & 160 & t.s. & Full \\
\hline Minimus & 0 & & 1059 & t.s. & Part & 0 & & & 160 & t.s. & Full \\
\hline Quadriannulatus & 0 & & 1045 & t.s. & Part & 0 & & & 160 & t.s. & Full \\
\hline Sinensis & 0 & & 1795 & t.s. & Full (?) & 0 & & & 143 & t.s. & Part \\
\hline Stephensi & 0 & & 1903 & t.s. & Full (?) & 345 & EU244871 & Full & 160 & t.s. & Full \\
\hline Species & ITS2 “L” & ITS2 “S” & ITS2 “C” & $28 \mathrm{~S}$ “L” & $28 \mathrm{~S}$ "S" & $28 S^{~ " C " ~}$ & NTS “L” & & & & \\
\hline Albimanus & 244 & L78065 & Full & 4022 & t.s. & Full & 0 & & & & \\
\hline Arabiensis & 434 & DQ287772 & Full & 1550 & t.s., U10138, [45] & Part & 1398 & & & & \\
\hline Atroparvus & 308 & AY050640 & Full & 0 & & & 0 & & & & \\
\hline Christyi & 419 & GQ870324 & Full & 0 & & & 0 & & & & \\
\hline Culicifacies & 368 & AY427754 & Full & 553 & t.s. & Part & 0 & & & & \\
\hline Dirus & 506 & DQ629915 & Full & 537 & AF41781 [43] & Part & 0 & & & & \\
\hline Epiroticus & 572 & AF469855 & Full & 0 & & & 0 & & & & \\
\hline Farauti & 564 & EF042721 [46] & Full & 546 & AF417815 [43] & Part & 0 & & & & \\
\hline Funestus & 724 & JN994135 & Full & 3445 & t.s. & Part & 0 & & & & \\
\hline Gambiae & 434 & X67157 & Full & 4021 & t.s. & Full & 1733 & & & & \\
\hline Maculatus & 363 & AY803346 & Full & 391 & AY120851 & Part & 0 & & & & \\
\hline Melas & 437 & GQ870314 & Full & 440 & AF087512 [47] & Part & 1118 & & & & \\
\hline Merus & 437 & GQ870313 & Full & 440 & AF087514 [47] & Part & 862 & & & & \\
\hline
\end{tabular}


Table 1 The rDNA repeat in 17 anophelines (Continued)

\begin{tabular}{|c|c|c|c|c|c|c|c|}
\hline minimus & 381 & JN975457 & Full & 811 & t.s. & Part & 0 \\
\hline Quadriannulatus & 465 & JN994146 & Full & 440 & AQU10137 [47] & Part & 1540 \\
\hline Sinensis & 469 & GU384695 [46] & Full & 4166 & t.s. & Full & 2896 \\
\hline Stephensi & 466 & AY157316 & Full & 4096 & t.s. & Full & 0 \\
\hline
\end{tabular}

The Table summarizes the data for the rDNA segments ETS, 18S, ITS1, 5.8S, ITS2, 28S and NTS. "L" includes the length of the sequence assembled for the corresponding DNA segment in base pairs, "S" the source of the sequence and " $\mathrm{C}$ " its completeness.

Full: full length of genomic segment available; part.: only partial sequence of the genomic segment available; t.s.: this study; number in square brackets: published reference; alphanumeric number: Genbank/EMBL

accession number. Accession numbers in italics refer to sequences obtained from public databases (Genbank/EMBL) for which no published reference is indicated. The question marks refer to the uncertainty as to the completeness of the sequence (see Results). 
long transcribed segment [14] that is later removed giving rise to two distinct small RNA species that interact to perform the same function of the "canonical" contiguous $5.8 \mathrm{~S}$ ribosomal RNA, that interacts with specific ribosomal proteins during translation [50]. Although "split" 5.8S rRNA genes have been described in Drosophila, they should not be considered a common characteristic of diptera. As a matter of fact, in six culicidae examined to date, none was identified in which the mature $5.8 \mathrm{~S}$ rRNA gene was made out of the two individual, processed species $[48,51]$.

BLAST searches of both the assembled genomes and the SRA collections of reads that were generated in this project, allowed us to identify the $5 \mathrm{~S}$ rRNA gene homologues in all species examined; in 16 out of 19 we were able to assemble a segment coding for the full $5.8 \mathrm{~S}$ species. Initially we used the $D$. melanogaster sequence as a query, and then switched to that of $A$. gambiae once this was unambiguously identified. The sequences shown in Figure 1 show alignments of consensus sequences for each individual species; an overall consensus sequence for all anophelines was assembled from those of the 19 species examined. We stress here that the consensus of each individual taxon is based on the BLAST searches of the primary sequence reads; the output was obviously biased towards sequences that were more similar to the BLAST query; they are therefore not to be considered as "statistical representatives" of all reads present in the SRA database. Not unexpectedly, as seen in Figure 1 a very high degree of sequence conservation is apparent which, overall, ranges from $100 \%$ in comparisons between members of the A. gambiae s.l. species complex, to $\sim 89 \%$ when the sequence of $A$. darlingi is compared to the consensus sequence determined from all species examined (average $>96 \%$ ). It should also be noted that most of the polymorphisms seen in A. darlingi are clustered towards the $3^{\prime}$ end of the mature $5.8 \mathrm{~S}$ molecule, following the pattern detected for the overall comparison: we have determined a total of 42 polymorphic sites, of which $7(17 \%)$ are found in the $5^{\prime}$-most 60 nucleotides, $13(31 \%)$ in the next 60 bases and the remaining ones over the last segment of the gene.

As described for the only anopheline that had previously been studied, A. pseudopunctipennis [52] as well as one unnamed species [48], our sequence analysis and comparisons to the $5.8 \mathrm{~S}$ gene of $D$. melanogaster suggest that the $5.8 \mathrm{~S}$ gene is not interrupted in any of the 19 species examined: Similarity to the fruit fly gene drops after nucleotide 122 (not shown), while it is maintained throughout the anophelines. Analysis of BLAST searches performed on transcribed sequences in several species suggest that two main classes of $5.8 \mathrm{~S}$ rRNA are present in the species analyzed, with a length of 159 and 160 nucleotides, although reads corresponding to molecules that are 20 nucleotides longer can be detected at a ratio of about 1:10 compared to the shorter ones (see Figure 1).

\section{The 28S RNA genes}

The results of the 28S RNA gene analysis are also summarized in Table 1 and Additional file 2. To identify the 28S RNA genes, a similar procedure to that chosen for the $18 \mathrm{~S}$ genes was followed. It was first guided by the $28 \mathrm{~S}$ gene of the fruitfly, which is 3945 bp long [14]. Unfortunately, the procedure used for identifying these sequences by BLASTing the assembled genomes as well as the SRA collections of reads was not as successful as with the $18 \mathrm{~S}$ rRNA and the 5.8 rRNA genes. More precisely, only in 4 out of 17 species analyzed (A. albimanus, A. gambiae, $A$. sinensis, $A$. stephensi) were we able to identify a complete gene and in one species (A. funestus) a large part of the $28 \mathrm{~S}$ gene (Table 1 ). In 9 other species we recognized shorter segments, their length ranging from $391 \mathrm{bp}$ to $1550 \mathrm{bp}$, while no sufficient results were retrieved for the 3 remaining species (namely $A$. atroparvus, A. christyi and A. epiroticus). The assemblies in VectorBase did not contain complete genes. We assume that the failure to retrieve complete sequences in most genomes examined is due, as mentioned earlier, to the presence of interruptions in the contiguity of the $28 \mathrm{~S}$ genes from the insertion of non-ribosomal DNA into them. We decided to only list here (Additional file 2) genes for which an unequivocal assembly can be presented.

\section{The spacers}

Spacer regions of the rDNA repeat were early on identified as excellent tools for the identification of cryptic taxa in anophelines [53]. This was an important technical development given that mosquito (and other arthropod) vectors are often members of species complexes whose members are difficult to distinguish. For the purpose of vector control it is important to be able to differentiate easily between vector and non-vector members of those complexes [47]. We therefore invested effort in identifying and classifying spacer regions. It should be noted that this was an extremely difficult and, often, unsuccessful exercise; the reason was that the spacer regions have undergone a substantial sequence diversification throughout evolution. We therefore stress that even in the case of the ITS2, the spacer separating the $5.8 \mathrm{~S}$ and the $28 \mathrm{~S}$ genes, which we identified in all species studied through corresponding entries in Genbank, we cannot absolutely ascertain the validity of the database records. BLASTing both SRAs and VectorBase assemblies often yielded results that could not be validated: discontinuities resulted in "jumps" from the ribosomal locus into other, non-identified regions of the genome (i.e. sequences initially considered to be contiguous were eventually found to be derived from -non-linked chromosomal segments). This is 
(See figure on previous page.)

Figure 1 Alignments of genes encoding the 5.8S ribosomal RNA. The species examined are shown at the left before the sequences. Nucleotides highlighted in green differ from those found at the corresponding position in the consensus sequence. Dashes indicate gaps introduced to improve the alignment, dots to sequence that was not identified. Capitalized letters in the consensus sequence indicate the extent of the 5.8S RNA in D. melanogaster. The three underlined nucleotides highlighted in yellow in the Anopheles consensus sequence point to the terminal nucleotides of the three RNA species identified through the analysis of RNAseq experiments. The base numbering refers to the consensus sequence.

particularly important, because the ITS2 spacer is the one that is mostly used for phylogenetic studies [47]. The Genbank entries for the ITS2 region have lengths ranging from 244 bp to 724 bp (Table 1).

The hunt for ITS1 (i.e. the region between the $18 \mathrm{~S}$ and the $5.8 \mathrm{~S}$ genes), as well as for the NTS and ETS, were even less successful. In no cases were we able to identify the DNA sequences by analyzing the new data obtained through the "16 Anopheles genomes project"; since querying with available sequences never yielded any positive results, we attempted "walks", but these equally led to the failure of identifying contiguous segments. Other than blaming potential miss-assemblies, pointing to the reasons for that failure would be sheer speculation (e.g. insertions of repeated sequences, and others) Thus, Table 1 only lists sequences for those spacers that had been earlier deposited in databases or published (Genbank Accession numbers in Table 1 and $[2,45,46,54-56])$.

Finally, the only anopheline species for which a complete intergenic spacer (NTS plus ETS) has ever been described is A. sinensis, its total length being $2896 \mathrm{bp}$. We compared the sequence of this segment to the partial sequences of the spacers available for five members of the gambiae complex (not shown). Only when several gaps were introduced along the segments closest to the $3^{\prime}$ end of the $28 \mathrm{~S}$ gene could some regions of, possibly, insignificant similarity be observed; however, when the NTS segments of the five members of the gambiae complex were compared to each other, extensive similarities were evident. This was particularly true, again, for the segments closest to the $3^{\prime}$ end of the $28 \mathrm{~S}$ gene.

\section{The 5S rRNA genes}

The eukaryotic 5S rRNAs, with lengths ranging from 115 to 125 nucleotides, are not related to the prokaryotic RNA species of the same name (see [57]). In D. melanogaster the mature 5S rRNA molecule is 120 bases long, stemming from a primary transcript of 135 bases that is post-transcriptionally shortened from its $3^{\prime}$ end [57-59]. About 100 copies of the gene encoding this rRNA are clustered at the cytogenetic locus 56 F1-56 F2; they are arranged as tandem repeats of a unit length of about 375 bp consisting of the mature RNA-coding segment and a spacer DNA $[16,60]$. In all insects analyzed so far sizes of the mature RNA are conserved, while the length of the overall repeat usually represents a multiple of a nucleosome length (core plus spacer). In addition to the functional constrains on the actual 5S RNA molecule stemming from its involvement in the translation machinery through direct interactions with the $18 \mathrm{~S}$ molecule (see [61]) the repeat length may be dictated by the potential phasing of nucleosomes [62], participating in the regulation of the transcription by RNA Polymerase III [63].

Little, so far, is known about 5S RNA genes in mosquitoes and no entry describing the complete or partial sequence of this RNA class is available in nucleic acid databases. To isolate the $5 \mathrm{~S}$ rRNA gene we again used the $D$. melanogaster mature molecule to query the different genomes in BLAST searches of the SRAs. We succeeded in assembling the individual sequence of the mature 5S RNA genes in 19 genomes. A "consensus" sequence was also assembled for all species analyzed (Figure 2).

Starting from the $5^{\prime}$ end of the fruit fly gene, we detected a high degree of similarity across all species studied (Figure 2). The sequences are absolutely collinear for 124 bases, with one extra nucleotide appearing at position +125 in $A$. darlingi and A. sinensis. We interpret this "insertion" to perhaps represent the first base of the intergenic spacer, although the mature RNA could well be shorter: searches of RNA sequences are inconclusive and need additional experimental information to be interpreted. The majority of the BLAST hits of RNAseq SRA reads showed molecules that extended to nucleotide \#121, although we could detect both shorter, up to \#115, and longer ones, up to \#139 (not shown). These "aberrant" molecules could represent errors in either transcription or maturation of the 5S RNAs. Nevertheless, we think that a short U-rich sequence (CTTTT) downstream of the presumed mature RNA, which is equidistant to a similar sequence in $D$. melanogaster, could represent the canonical signal for the end of transcription [64-66]. Interestingly, the segments between nucleotide 121 and the CTTTT sequence are highly polymorphic, including two indels of one and two bases in four of the species studied, as mentioned above.

We assembled a consensus sequence for for all 19 species examined (Figure 2). We stress here that this consensus is based on the BLAST searches of the primary sequence reads and not the assembled genomic sequences. The degree of similarity over the first 121 base pairs, across 


albimanus
arabiensis
atroparvus
christyi
coluzzii
culicifacies
darlingi
dirus
epiroticus
farauti
funestus
gambiae
maculatus
melas
merus
minimus
quadriannulatus
sinensis
stephensi

Anopheles consensus

GTCAACGACCATACCATGTTGAAAACACCGGTTCTCGTCCGATCACCGAAGTTAAGCAAC GTCAACGACCATACCATGTTGAAAACACCGGTTCTCGTCCGATCACCGAAGTTAAGCAAC GTCAACGACCATACCATGTTGAAAACAAAGGTTCTCGTCCCATCACCGAAGTTAAGCAAC GTCAACGACCATACCATGTTGAAAACACCGGTTCTCGTCCGATCACCGAAGTTAAGCAAC GTCAACGACCATACCATGTTGAAAACACCGGTTCTCGTCCGATCACCGAAGTTAAGCAAC GTCAACGACCATACCATGTTGAACACACCGGTTCTCGTCCGATCACCGAAGTTAAGCAAC GTCAACGACCATACCATGCTGAAAACACCGGTTCTCGTCCGATCACCGAAGTTAAGCAGC GTCAACGACCATACCATGTTGAAAACACCGGTTCTCGTCCGATCACCGAAGTTAAGCAAC GTCAACGACCATACCATGTTGAAAACACCGGTTCTCGTCCGATCACCGAAGTTAAGCAAC GTCAACGACCATACCATGTTGAAAACACCGGTTCTCGTCCGATCACCGAAGTTAAGCAAC GTCAACGACCATACCATGTTGAACACACCGGTTCTCGTCCGATCACCGAAGTTAAGCAAC GTCAACGACCATACCATGTTGAAAACACCGGTTCTCGTCCGATCACCGAAGTTAAGCAAC TTCAACGACCGTACCATGTTAAACACACCGGACCTTGTCCATTCACCGAAGTTAAGCAAC GTCAACGACCATACCATGTTGAAAACACCGGTTCTCGTCCGATCACCGAAGTTAAGCAAC GTCAACGACCATACCATGTTGAAAACACCGGTTCTCGTCCGATCACCGAAGTTAAGCAAC GTCAACGACCATACCATGTTGAACACACCGGTTCTCGTCCGATCACCGAAGTTAAGCAAC GTCAACGACCATACCATGTTGAAAACACCGGTTCTCGTCCGATCACCGAAGTTAAGCAAC GTCAACGACCATACCATGTTGAAAACACCGGTTCTCGTCCGATCACCGAAGTTAAGCAAC GTCAACGACCATACCATGTTGAACACACCGGTTCTCGTCCGATCACCGAAGTTAAGCAAC |||||||| |||||| | || ||| ||| || |||| ||||||||||||||| | GTCAACGACCATACCATGTTGAAAACACCGGTTCTCGTCCGATCACCGAAGTTAAGCAAC - 60

ATCGGGCATGGCTAGTACTTAGGTGGGTGACCACTTGGGAAAACCATGTGTCGTTGGCAT ATCGGGCATGGCTAGTACTTAGGTGGGTGACCACTTGGGAAAACCATGTGTCGTTGGCAT ATCGGGCATGGTTAGTACTTAGGTGGGTGACCACTTGGGAACGCCATGTGTCGTTGGCAT ATCGGGCATGGCTAGTACTTAGGTGGGTGACCACTTGGGAAAACCATGTGTCGTTGGCAT ATCGGGCATGGCTAGTACTTAGGTGGGTGACCACTTGGGAAAACCATGTGTCGTTGGCAT ATCGGGCATGGCTAGTACTTAGGTGGGTGACCACTTGGGAAAACCATGTGTCGTTGGCAT ATTGGGCATGGTTAGTACTTAGATGGGTGACCGCTTGGGAACGCCATGTGTCGTTGGCAT ATCGGGCATGGCTAGTACTTAGGTGGGTGACCACTTGGGAAAACCATGTGTCGTTGGCAT ATCGGGCATGGCTAGTACTTAGGTGGGTGACCACTTGGGAAAACCATGTGTCGTTGGCAT ATCGGGCATGGCTAGTACTTAGGTGGGTGACCACTTGGGAAAACCATGTGTCGTTGGCAT ATCGGGCATGGCTAGTACTTAGGTGGGTGACCACTTGGGAAAACCATGTGTCGTTGGCAT ATCGGGCATGGCTAGTACTTAGGTGGGTGACCACTTGGGAAAACCATGTGTCGTTGGCAT ATCGGGCATGGCTAGTACTTAGGTGGGTGACCACTTGGGAAAACCATGTGTCGTTGGCAT ATCGGGCATGGCTAGTACTTAGGTGGGTGACCACTTGGGAAAACCATGTGTCGTTGGCAT ATCGGGCATGGCTAGTACTTAGGTGGGTGACCACTTGGGAAAACCATGTGTCGTTGGCAT ATCGGGCATGGCTAGTACTTAGGTGGGTGACCACTTGGGAAAACCATGTGTCGTTGGCAT ATTGGGTATGGCTAGTACTTAGGTGGGTGACCACTTAGGAAAACCATGTGTCGTTGGCAT ATCGGGCATGGTTAGTACTTAGGTGGGTGACCACTTGGGAACACCATGTGTCGTTGGCAT ATCGGGCATGGCTAGTACTTAGGTGGGTGACCACTTGGGAAAACCATGTGTCGTTGGCAT || ||| |||| ||||||||||||||||||||||||||||||||||||||||||

Anopheles consensus ATCGGGCATGGCTAGTACTTAGGTGGGTGACCACTTGGGAAAACCATGTGTCGTTGGCAT - 120

albimanus
arabiensis
atroparvus
christyi
coluzzii
culicifacies
darlingi
dirus
epiroticus
farauti
funestus
gambiae
maculatus
melas
merus
minimus
quadriannulatus
sinensis
stephensi
Anopheles consensus

CACC-ACСАACT--СТTTTGCCACCСGCССССTTCACССTTTCGCCCGCC СТCC-АССААСТ--СТTTTGCCAСССGCССССТTC.......... СTCC-АCСАACT--СTTTTGCCACCCGCССССTTCACССTTTCGCCCGCC CACC-АCСАACT--СTTTTGCCACCCGCССССTTCACССTTTCGCCCGCC СTTC-ACСTTTTTGCTTTTCTCAGCCTCATCGGGGATGTGTTTGGTCG. .

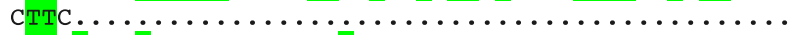

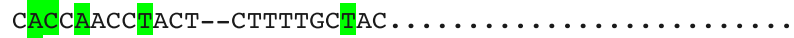
СТCС-АССААСТ--СТTTTGCCACCCGCССССTTCACССTTTCGCCCGCC

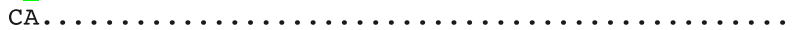
CACC-ACAAACA--СTTTTGCCACCCGCCCССTTCACCATTGCGCCCGCC САСC-АССАССТ--СТTTTGCCACССGCССССТTСАСССТTTC...... CTTC-ACCTTTTTGCTTTTCTCAGCCTCATCGGGGATGTGTTTGGTCG. .

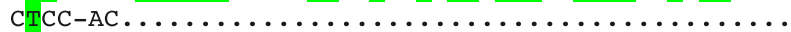
САСС-АСААТСT--СТTTTGAAACCCGCССССTTCGСССTTTCGCCCGC. CACC-АCСАACT--СТTTTGCCACCCGCCСССTTCACССTTTCGCCCGCC

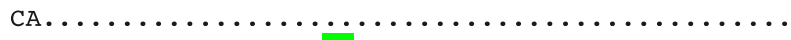
CACC-АСАAАCT--СТTTTGAAACCCGCССССTTCACССTTTCGCCCGCC САССТСССАAСT--СТTTTGCCACCCG.............

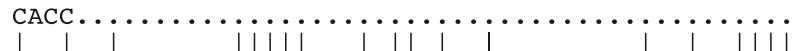

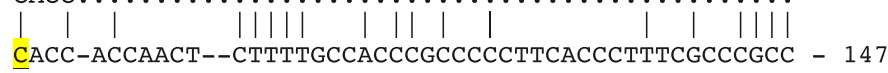

Figure $\mathbf{2}$ (See legend on next page.) 
all anopheline species studied, is $\sim 85 \%$ (cumulative number of nucleotides that are different from the "consensus") although, of course, the similarity between any two species is, indeed, much higher than that.

Looking at the sequence of the first 121 nucleotides (Figure 2), the species whose 5S rDNA sequence differs most from the consensus of the 19 genomes analyzed are A. maculatus ( 8 nucleotides, all between bases 11 and 42), A. darlingi (7 nucleotides, all between bases 19 and 102) and A. atroparvus (6 nucleotides, all between bases 1 and 102). A. quadriannulatus has three bases different from the consensus, $A$. sinensis has 2, while only one base pair differentiates minimus, stephensi and culicifacies from the consensus. The most common polymorphism affects nucleotide \#24 (five times), while none of the others is found in more than three species. Finally, comparing $D$. melanogaster to the anopheline consensus sequence, one notices 32 differences between them scattered over the first 120 nucleotides, or a conservation of 73\% (not shown).

In the A. gambiae AgamP4 assembly available at VectorBase, sequences similar to the $5 \mathrm{~S}$ ribosomal RNA are found at the cytogenetic locus $23 \mathrm{C}$; like in the fruit fly, the genes are unlinked from the remaining rRNA genes. The AgamP4 assembly indicates a series of $\sim 500$ bp long tandem repeats, which are wrongly annotated as being 5.8 rRNA genes of a length of 115 bp each. Although longer than that described for the fruit fly, the overall length of the repeat is consistent with the theory of nucleosome phasing, whereby three nucleosomes of $\sim 167 \mathrm{bp}$ could be localized on each of the repeats, instead of two as in D. melanogaster. This would be a situation similar to Xenopus laevis where the repeat of the $5 \mathrm{~S}$ gene is equal to four nucleosomes [67].

\section{Phylogenetic analysis}

The absence of complete rDNA sequences for some of the species combined with the fact that the alignment procedure led to remove a large part of them as unaligned (the alignment was ambiguous) made us decide to restrict our analysis to a concatenated sequence that included a portion of the nuclear ribosomal sequences produced in this study and segments of the mitochondrial $16 \mathrm{~S}$ rDNA gene and the COI genes. Our aim was to identify the origin of these ribosomal sequences and also to evaluate the produced phylogenetic relationships based on the previously published data. A total of 5,145 base pairs (bp) for all loci (5S rRNA: $170 \mathrm{bp}, 18 \mathrm{~S}$ rRNA:
1332 bp, 28SrRNA: 826 bp, 16SrRNA: 1338 bp, and COI: $1479 \mathrm{bp}$ ) were analyzed for 18 taxa (17 ingroup taxa of the genus Anopheles and one outgroup taxon D. melanogaster). The ingroup alignment contained 921 variable and 395 parsimony informative sites, while when the outgroup taxon were included they were raised to 1229 and 472, respectively. Maximum Likelihood $(-\ln L=16177.91)$, Bayesian Inference $(-\ln L=16201.02)$ and Neighbor Joining analyses of the concatenated data produced similar topologies (see Figure 3). Although without very good statistical support (posterior probabilities in BI and bootstrap values in ML and NJ), the produced tree revealed several groups of species. One of them is the Anopheles gambiae complex that includes A. gambiae that branched off first, A. merus, A. arabiensis, A. melas, and A. quadriannulatus, which is in agreement with previous published analyses [45]. The other major group comprises 7 species in which $A$. maculatus seems to be sister taxon to $A$. stephensi $(1.00 / 95 / 59)$ and $A$. culicifacies to A. minimus $(0.99 / 77 /<50)$.

\section{The snoRNA genes}

snoRNAs are a family of small nucleolar RNA species that are involved in post-transcriptional modification of other ncRNA classes, primarily rRNAs, but possibly also tRNAs and snRNAs (see [68]). Two main classes are known, the C/D box snoRNAs, which are primarily associated with methylation of target RNAs, and the H/ACA box snoRNAs that are mostly involved in pseudouridilation processes [69]. To date, no published reports exist describing any of these RNA classes in insects other than Drosophila. We therefore initiated a search for snoRNAs in the genomes of the "16 Anopheles genomes project".

snoRNA genes are difficult to identify de novo in large genomes. For the prediction of C/D box snoRNA we concentrated on the usage of snoScan [25], a computational method that predicts the genes based on target recognition, in combination with SnoReport, a genomewide approach [33] that uses a combination of RNA secondary structure prediction and machine learning based on known snoRNAs; unfortunately, we found that SnoReport "overpredicted" snoRNA genes in all genomes analyzed (the numbers for all species were 4-6 times higher than those expected from comparisons to other organisms). Taking a conservative approach, we report here the results of the analysis of snoScan, although we can provide the SnoReport data on demand (see Additional file 3). 


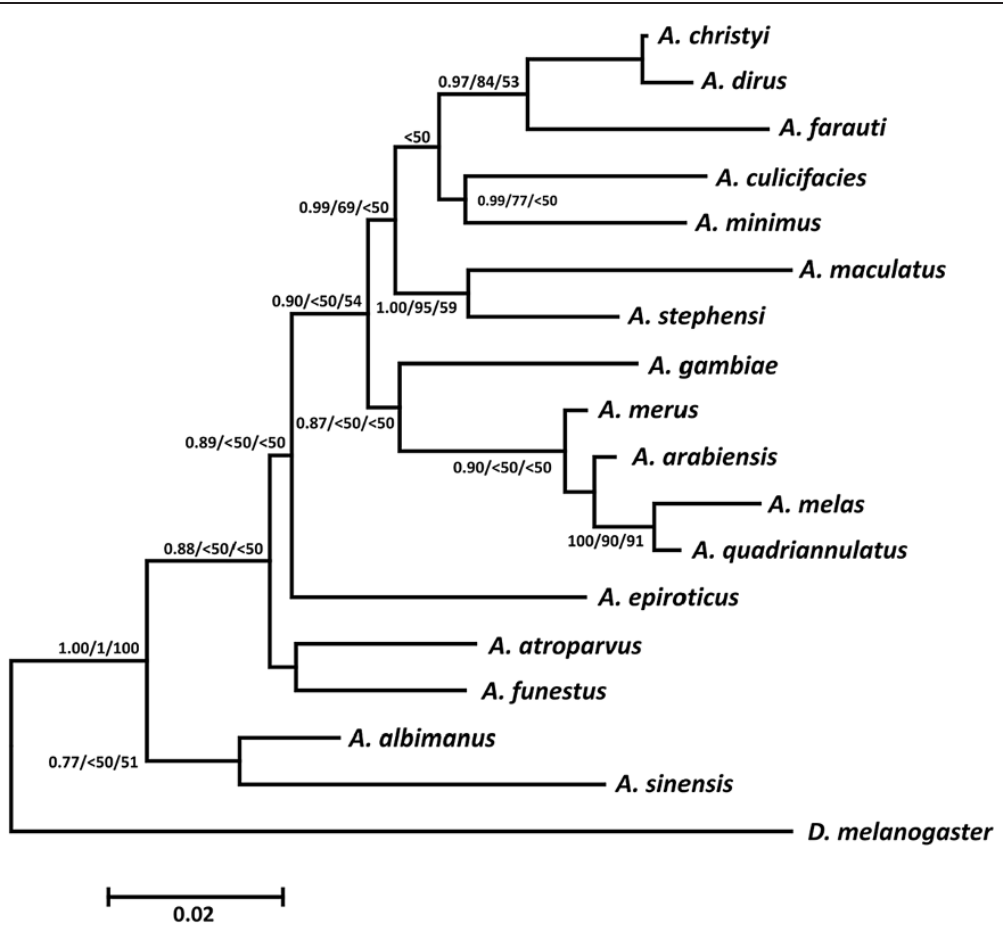

Figure 3 Bayesian Inference tree inferred by the concatenated dataset. The numbers on the branches indicate posterior probabilities and bootstrap supports (BI/ML/NJ).

snoScan requires the input of "target" RNA sequences; in our cases the sequences were "extracted" from the consensi of the $18 \mathrm{~S}$ and $28 \mathrm{~S}$ rDNA determined. In cases in which the rDNA sequences available were considered to be too short, we used instead the corresponding nucleic acids from the closest neighbor in evolutionary terms [11]. Also, in the case of the two A. gambiae strains and $A$. coluzzii, the same consensus sequence of A. gambiae was used (see Table 2).

Unexpectedly, although we aimed at predicting both C/D box and H/ACA box snoRNAs with snoScan, only sequences corresponding to C/D box-containing snoRNA genes could be identified. We assume that this is due to the C/D box snoRNAs' well-conserved motifs and the 10-21 nt complementary guide sequences that lie between the motifs [70], which enabled the successful computational screen. In contrast, H/ACA guide snoRNAs are shorter and have less well-conserved primary sequence motifs, therefore being harder to identify.

Table 2 lists the results of the analysis for predicted C/D box snoRNAs in the Anopheles taxa studied. The lowest numbers of snoRNA genes targeting 18S RNA predicted were 23 (A. dirus) and 29 (A. minimus), while the highest were 168 (A. gambiae PEST strain) and 130 (A. albimanus). If only the highest stringency predictions are considered, the number of genes drops to numbers lower than 23 for all taxa examined. The number of predictions per 100 bases of target RNA ranges from 2.6 to 8.3 , the latter number referring to the usage of the A. gambiae PEST strain assembly. It should be emphasized that that particular genome is represented by preNGS whole genome sequence; this "technical" difference might be the reason for higher predictions; we could speculatively state that this might be due to better quality sequencing.

The total number of putative snoRNA genes targeting 28S RNA can be seen in Table 2. Here, not unexpectedly, the taxa with the lowest numbers of predicted genes are the ones for which a shorter target was provided. The number of predictions per 100 nucleotides of target are not significantly different among the different taxa.

In Drosophila melanogaster $98 \mathrm{C} / \mathrm{D}$ box snoRNAs have been annotated in the current (May 9, 2014) release of FlyBase [71], although it is possible that more exist. 64 of them have $28 \mathrm{~S}$ rRNA as a target, 30 target $18 \mathrm{~S}$ rRNA while the remaining four are thought to be involved in the methylation of U6 snRNA (2x), U2 snRNA and 5.8S rRNA. Interestingly, but not unexpectedly, we detect in the case of anophelines a high degree of similarity between the snoRNA genes in closer-related species. Within the members of the gambiae complex, more than $30 \%$ of the genes are 100\% identical (not 
Table 2 snoRNA genes in 19 anopheline taxa

\begin{tabular}{|c|c|c|c|c|c|c|c|c|}
\hline Species & $18 \mathrm{~S}$ target from: & Length of $18 \mathrm{~S}$ target & No stem & Possible stem & Terminal stem & Strong stem & Total & Genes/kb \\
\hline Albimanus & & 1977 & 30 & 17 & 62 & 19 & 128 & 6.5 \\
\hline Arabiensis & & 1981 & 20 & 10 & 51 & 21 & 102 & 5.1 \\
\hline Atroparvus & & 1965 & 15 & 8 & 40 & 7 & 70 & 3.6 \\
\hline Christyi & & 583 & 3 & 1 & 5 & 1 & 10 & 1.7 \\
\hline Coluzzii & Gambiae & 2015 & 20 & 11 & 38 & 25 & 94 & 4.7 \\
\hline Culicifacies & Funestus & 1817 & 14 & 4 & 19 & 10 & 47 & 2.6 \\
\hline Dirus & & 594 & 8 & 2 & 11 & 2 & 23 & 3.9 \\
\hline Epiroticus & & 1786 & 12 & 12 & 19 & 12 & 55 & 3.1 \\
\hline Farauti & & 2046 & 26 & 19 & 46 & 11 & 102 & 5 \\
\hline Funestus & & 1817 & 14 & 9 & 23 & 8 & 54 & 3 \\
\hline Gambiae PEST & & 2015 & 31 & 13 & 94 & 22 & 160 & 7.9 \\
\hline Gambiae S & & 2015 & 24 & 13 & 43 & 22 & 102 & 5.1 \\
\hline Maculatus & & 1950 & 9 & 5 & 29 & 9 & 52 & 2.7 \\
\hline Melas & Gambiae & 2015 & 13 & 11 & 41 & 23 & 88 & 4.4 \\
\hline Merus & & 1518 & 19 & 11 & 43 & 17 & 90 & 5.9 \\
\hline Minimus & & 1059 & 7 & 6 & 13 & 4 & 30 & 2.8 \\
\hline Quadrianulatus & & 1045 & 10 & 7 & 20 & 12 & 49 & 4.7 \\
\hline Sinensis & & 1795 & 14 & 5 & 29 & 6 & 54 & 3 \\
\hline Stephensi & & 1903 & 30 & 13 & 46 & 10 & 99 & 5.2 \\
\hline Species & $28 \mathrm{~S}$ target from: & Length of $28 \mathrm{~S}$ target & No stem & Possible stem & Terminal stem & Strong stem & Total & Genes/kb \\
\hline Albimanus & & 4022 & 80 & 43 & 158 & 32 & 320 & 8 \\
\hline Arabiensis & & 1110 & 17 & 8 & 21 & 8 & 55 & 5 \\
\hline Atroparvus & Sinensis & 4069 & 40 & 35 & 76 & 22 & 174 & 4.3 \\
\hline Christyi & & 524 & 4 & 3 & 9 & 3 & 19 & 3.6 \\
\hline Coluzzii & Gambiae & 3440 & 63 & 30 & 82 & 36 & 220 & 6.4 \\
\hline Culicifacies & & 560 & 7 & 6 & 6 & 1 & 20 & 3.6 \\
\hline Dirus & Farauti & 546 & 8 & 6 & 25 & 12 & 53 & 9.7 \\
\hline Epiroticus & Christyi & 524 & 4 & 4 & 12 & 8 & 28 & 5.3 \\
\hline Farauti & & 546 & 9 & 3 & 12 & 5 & 29 & 5.3 \\
\hline Funestus & & 3445 & 43 & 21 & 53 & 16 & 134 & 3.9 \\
\hline Gambiae PEST & & 3440 & 75 & 39 & 126 & 52 & 300 & 8.7 \\
\hline Gambiae S & & 3440 & 66 & 35 & 98 & 29 & 236 & 6.9 \\
\hline Maculatus & & 351 & 2 & 2 & 7 & 0 & 11 & 3.1 \\
\hline Melas & & 440 & 4 & 1 & 6 & 1 & 12 & 2.7 \\
\hline Merus & & 440 & 5 & 2 & 10 & 2 & 19 & 4.3 \\
\hline Minimus & & 811 & 7 & 5 & 15 & 2 & 31 & 3.8 \\
\hline Quadrianulatus & & 440 & 3 & 2 & 8 & 1 & 14 & 3.2 \\
\hline Sinensis & & 4096 & 42 & 15 & 61 & 12 & 129 & 3.1 \\
\hline Stephensi & & 3801 & 56 & 21 & 91 & 21 & 189 & 5 \\
\hline Sinensis & Sinensis & 4096 & 42 & 15 & 61 & 12 & 129 & 3.1 \\
\hline Stephensi SDA & Stephensi & 3801 & 54 & 20 & 92 & 21 & 189 & 5.0 \\
\hline
\end{tabular}

The table lists both the taxa examined and those whose sequences were used as targets if different (see Results). The numbers refer to the individual candidate genes containing the different snoRNA structures as well as their total and the number of putative genes per 100 bp of target sequence used. The length of the target sequences is also indicated. 
shown). A few snoRNAs are also shared between more distantly related species (e.g. A. epiroticus has one gene that has an identical sequence with one in $A$. farauti).

\section{The tRNA genes}

In all organisms examined so far tRNA genes constitute the largest gene family; membership ranges from a few hundreds to several thousands (see [72] in different species examined. The extremely conserved "cloverleaf structure" combined with the preserved localization of functional sequence features on it $[72,73]$ have made it easy, early on, to devise strategies for the computational identification of these genes from a large variety of organisms. Although there is a rough correlation between the number of tRNA genes and the "complexity" of an organism, the actual number of tRNA genes [74] is not directly proportional to the genome size as can be exemplified when one looks at diptera. While $D$. melanogaster, with a genome size of $\sim 125 \mathrm{Mb}$ contains between 590 and 950 tRNA genes [75]. Aedes aegypti (genome size: $\sim 1.3 \mathrm{~Gb})$ contains 906 and A. gambiae 441 with a $\sim 270 \mathrm{Mb}$ long genome [76]. The latter numbers include 111 and 1 pseudogenes, respectively.

The findings of this analysis are reported in Additional file 4 and summarized in Table 3. Gene numbers in different species should be considered as approximate since, in spite of the solid methodology used, gene assemblies rarely represent the reality, even of the actual specimens sequenced. This can be exemplified by the greatly differing number of tRNA genes determined for A. gambiae, when the assemblies of two different strains present in VectorBase were analyzed (see Table 3). While we found 389 genes in the AgamS1 assembly of the $\mathrm{S}$ form Pimperena strain, the PEST strain assembly (AgamP4) yielded 464 genes, i.e. a number that is $19.3 \%$ higher. Interestingly, using the same software as we used in the present study, Behura \& Severson [76] in an earlier gene set of the AgamP4 assembly identified 24 fewer tRNA genes (see Table 3). Also, these authors identified one pseudogene versus 11 in the present study, and no tRNA for Selenocysteine, while we identified one such gene. The number of tRNA genes computed ranged from 125 for A. minimus to 464 in the A. gambiae PEST strain. The average number is 331.4 tRNA genes per genome, or 1.5 tRNA genes per $\mathrm{Mb}$ of genomic DNA. As can also be seen in Table 3, the only species examined that is unusual is the Asian mosquito A. maculatus. Here, the number of tRNA genes identified is 125 , or $\sim 37.7 \%$ of the average number and, the number of genes per $\mathrm{Mb}$ is also substantially lower than the average (0.9). One should note that this species also has the second-smallest genome assembled. The low number of genes in the genome of $A$. maculatus also leads to statistically significant but, probably, biologically less relevant differences in the relative abundance of isoacceptors for some amino acids (see Table 3).

Finally, we should point to the fact that the genomes of both the $A$. gambiae PEST strain as well as $A$. minimus were found to contain a number of valine tRNA genes that is significantly higher (about double) than of the other species. Surprisingly enough, this is neither the case for the Pimperena strain, nor the remaining 5 members of the complex, including A. coluzzii, a taxon that was recently elevated to a species [77], having previously been considered to be a "molecular form" of A. gambiae s.s. [78]. We cannot suggest an explanation for this finding other than, potentially, an artifact due to the genome assembly.

\section{The miRNA genes}

miRNAs are a class of small RNA molecules that have been found to play a crucial role in the regulation of gene expression in metazoans and plants [79]. miRNAs are transcribed as precursor molecules that undergo processing via mechanisms that have been studied [80]. The so-called pre-miRNA hairpins, are the first discrete molecules of a length of 50-70 nucleotides to appear, and these are exported to the cytoplasm where they are processed to the 22-23 nucleotides long miRNA molecules. There, miRNAs pair to mRNA molecules leading to posttranscriptional silencing of protein-coding genes [81]. miRNAs may play crucial roles in vector-borne diseases: A number of miRNA molecules (and the genes that encode them) been recently reported in mosquitoes [82-85] and the biological role attributed to them also includes a hypothetical involvement in the regulation of pathogen-vector interactions such as Plasmodium bergheiA. gambiae [86] as well as processes more closely associated with the pathogenesis process [85].

The identification of bona fide miRNA molecules usually requires a complicated pipeline consisting of a computational search, the detection of the molecules among reads of small RNA sequencing surveys and, finally, the functional identification of the miRNA-target interactions. Given the fact that the present analysis was part of the "16 Anopheles genomes project", we had to concentrate on the first of the three approaches. We decided to take a rather conservative attitude in terms of calling the actual miRNA genes identified and used stringent criteria calling positives. We included in our analysis both $a b$ initio prediction software as well as homology searches of three kinds. Only when two of these pointed to a potential candidate sequence as being a miRNA would we accept the finding. The results of this analysis are summarized in Table 4 while Additional file 5 lists all putative miRNA genes identified.

Our pipeline yielded a number of putative miRNA genes. In case that this was possible, we annotated all miRNA genes identified with either the miRBase name 
Table 3 tRNA genes identified in 19 anopheline species

\begin{tabular}{|c|c|c|c|c|c|c|c|c|c|c|c|c|c|c|c|c|c|c|}
\hline \multirow[b]{2}{*}{ Anopheline species } & \multicolumn{10}{|c|}{ - > Aliphatic } & \multicolumn{4}{|c|}{ - > S-containing } & \multirow[t]{2}{*}{$P$} & \multirow[t]{2}{*}{$\Sigma$} & \multirow[t]{2}{*}{ M } & \multirow[t]{2}{*}{$\mathrm{F}$} \\
\hline & Gly & $\%$ & Val & $\%$ & Ala & $\%$ & Leu & $\%$ & Ile & $\%$ & Cys & $\%$ & Met & $\%$ & & & & \\
\hline Albimanus & 17 & 5.6 & 15 & 4.9 & 28 & 9.2 & 20 & 6.5 & 13 & 4.2 & 5 & 1.6 & 15 & 4.9 & 0 & 306 & 170.5 & 1.8 \\
\hline Arabiensis & 22 & 6.1 & 28 & 7.8 & 25 & 7.0 & 22 & 6.1 & 16 & 4.5 & 5 & 1.4 & 18 & 5.0 & 6 & 359 & 246.6 & 1.5 \\
\hline Atroparvus & 21 & 6.2 & 26 & 7.7 & 24 & 7.1 & 23 & 6.8 & 12 & 3.6 & 5 & 1.5 & 17 & 5.0 & 1 & 337 & 224.3 & 1.5 \\
\hline Christyi & 18 & 6.0 & 20 & 6.7 & 20 & 6.7 & 17 & 5.7 & 11 & 3.7 & 5 & 1.7 & 14 & 4.7 & 8 & 300 & 172.7 & 1.7 \\
\hline Coluzzii & 24 & 6.3 & 22 & 5.8 & 27 & 7.1 & 22 & 5.8 & 16 & 4.2 & 5 & 1.3 & 18 & 4.7 & 10 & 379 & 224.5 & 1.7 \\
\hline Culicifacies & 21 & 7.3 & 23 & 8.0 & 18 & 6.3 & 19 & 6.6 & 10 & 3.5 & 6 & 2.1 & 13 & 4.5 & 118 & 286 & 203.0 & 1.4 \\
\hline Darlingi & 10 & 4.4 & 12 & 5.3 & 16 & 7.0 & 14 & 6.1 & 9 & 3.9 & 3 & 1.3 & 11 & 4.8 & 0 & 228 & 134.7 & 1.7 \\
\hline Dirus & 23 & 6.7 & 23 & 6.7 & 26 & 7.5 & 23 & 6.7 & 12 & 3.5 & 5 & 1.4 & 16 & 4.6 & 3 & 345 & 216.3 & 1.6 \\
\hline Epiroticus & 18 & 5.6 & 22 & 6.9 & 24 & 7.5 & 19 & 5.9 & 13 & 4.1 & 5 & 1.6 & 16 & 5.0 & 67 & 320 & 223.5 & 1.4 \\
\hline Farauti & 22 & 6.2 & 25 & 7.1 & 22 & 6.2 & 23 & 6.5 & 14 & 4.0 & 5 & 1.4 & 17 & 4.8 & 0 & 354 & 181.0 & 1.9 \\
\hline Funestus & 17 & 5.9 & 24 & 8.4 & 18 & 6.3 & 15 & 5.2 & 10 & 3.5 & 6 & 2.1 & 12 & 4.2 & 0 & 286 & 225.2 & 1.3 \\
\hline Maculatus & 6 & 4.8 & 10 & 7.9 & 8 & 6.3 & 9 & 7.1 & 3 & 2.4 & 4 & 3.2 & 6 & 4.8 & 5 & 126 & 141.9 & 0.9 \\
\hline Melas & 20 & 5.7 & 23 & 6.6 & 26 & 7.4 & 24 & 6.9 & 16 & 4.6 & 5 & 1.4 & 17 & 4.9 & 15 & 349 & 227.4 & 1.5 \\
\hline Merus & 22 & 6.3 & 25 & 7.1 & 25 & 7.1 & 22 & 6.3 & 14 & 4.0 & 5 & 1.4 & 18 & 5.1 & 8 & 351 & 251.8 & 1. \\
\hline Minimus & 18 & 5.8 & 42 & 13.5 & 18 & 5.8 & 23 & 7.4 & 11 & 3.5 & 5 & 1.6 & 18 & 5.8 & 134 & 312 & 201.8 & 1.5 \\
\hline Gambiae AgamP4 & 29 & 6.2 & 65 & 14.0 & 28 & 6.0 & 28 & 6.0 & 15 & 3.2 & 5 & 1.1 & 21 & 4.5 & 11 & 465 & 278.0 & 1.7 \\
\hline Gambiae AgamP4* & 25 & 5.7 & 64 & 14.5 & 28 & 6.4 & 26 & 5.9 & 15 & 3.4 & 5 & 1.1 & 19 & 4.3 & 1 & 440 & 278.0 & 1.6 \\
\hline Gambiae AgamS & 27 & 6.9 & 26 & 6.7 & 29 & 7.5 & 28 & 7.2 & 14 & 3.6 & 5 & 1.3 & 21 & 5.4 & 13 & 389 & 236.4 & 1.6 \\
\hline Quadrianulatus & 22 & 6.2 & 25 & 7.0 & 25 & 7.0 & 22 & 6.2 & 14 & 3.9 & 4 & 1.1 & 17 & 4.8 & 7 & 357 & 283.8 & 1.3 \\
\hline Sinensis & 20 & 5.6 & 26 & 7.2 & 23 & 6.4 & 26 & 7.2 & 14 & 3.9 & 6 & 1.7 & 18 & 5.0 & 2 & 360 & 241.4 & 1.5 \\
\hline Stephensi & 18 & 5.6 & 27 & 8.3 & 19 & 5.9 & 17 & 5.2 & 12 & 3.7 & 5 & 1.5 & 16 & 4.9 & 83 & 324 & 225.4 & 1.4 \\
\hline Average aa per species & 20.0 & 6.0 & 27.3 & 8.0 & 22.7 & 6.8 & 21.0 & 6.4 & 12.6 & 3.8 & 5.0 & 1.6 & 16.1 & 4.8 & 23.4 & 331.4 & 218.5 & 1. \\
\hline
\end{tabular}

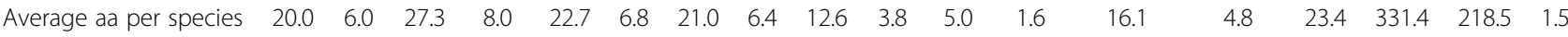

\begin{tabular}{|c|c|c|c|c|c|c|c|c|c|c|c|c|c|c|}
\hline \multirow[b]{2}{*}{ Anopheline species } & \multicolumn{8}{|c|}{ - > Acidic $\&$ their amide cont. aa } & \multicolumn{6}{|c|}{ - > Basic } \\
\hline & Asp & $\%$ & Asn & $\%$ & Glu & $\%$ & Gln & $\%$ & His & $\%$ & Arg & $\%$ & Lys & $\%$ \\
\hline Albimanus & 14 & 4.6 & 10 & 3.3 & 23 & 3.3 & 12 & 3.9 & 15 & 4.9 & 19 & 6.2 & 22 & 7.2 \\
\hline Arabiensis & 18 & 5.0 & 11 & 3.1 & 25 & 3.1 & 15 & 4.2 & 20 & 5.6 & 21 & 5.8 & 24 & 6.7 \\
\hline Atroparvus & 18 & 5.3 & 10 & 3.0 & 22 & 3.0 & 13 & 3.9 & 12 & 3.6 & 21 & 6.2 & 23 & 6.8 \\
\hline Christyi & 16 & 5.3 & 12 & 4.0 & 26 & 4.0 & 13 & 4.3 & 16 & 5.3 & 20 & 6.7 & 22 & 7.3 \\
\hline Coluzzii & 18 & 4.7 & 11 & 2.9 & 25 & 2.9 & 16 & 4.2 & 20 & 5.3 & 24 & 6.3 & 31 & 8.2 \\
\hline Culicifacies & 12 & 4.2 & 8 & 2.8 & 22 & 2.8 & 13 & 4.5 & 11 & 3.8 & 18 & 6.3 & 18 & 6.3 \\
\hline Darlingi & 12 & 5.3 & 5 & 2.2 & 16 & 2.2 & 8 & 3.5 & 16 & 7.0 & 14 & 6.1 & 17 & 7.5 \\
\hline Dirus & 16 & 4.6 & 10 & 2.9 & 26 & 2.9 & 15 & 4.3 & 13 & 3.8 & 24 & 7.0 & 24 & 7.0 \\
\hline Epiroticus & 16 & 5.0 & 9 & 2.8 & 23 & 2.8 & 14 & 4.4 & 15 & 4.7 & 20 & 6.3 & 23 & 7.2 \\
\hline Farauti & 18 & 5.1 & 11 & 3.1 & 27 & 3.1 & 15 & 4.2 & 12 & 3.4 & 21 & 5.9 & 25 & 7.1 \\
\hline Funestus & 13 & 4.5 & 7 & 2.4 & 22 & 2.4 & 13 & 4.5 & 13 & 4.5 & 19 & 6.6 & 19 & 6.6 \\
\hline Maculatus & 5 & 4.0 & 3 & 2.4 & 6 & 2.4 & 5 & 4.0 & 8 & 6.3 & 13 & 10.3 & 8 & 6.3 \\
\hline Melas & 18 & 5.2 & 13 & 3.7 & 22 & 3.7 & 14 & 4.0 & 14 & 4.0 & 23 & 6.6 & 25 & 7.2 \\
\hline Merus & 19 & 5.4 & 11 & 3.1 & 24 & 3.1 & 15 & 4.3 & 16 & 4.6 & 21 & 6.0 & 25 & 7.1 \\
\hline Minimus & 13 & 4.2 & 8 & 2.6 & 19 & 2.6 & 13 & 4.2 & 12 & 3.8 & 18 & 5.8 & 18 & 5.8 \\
\hline Gambiae AgamP4 & 26 & 5.6 & 14 & 3.0 & 28 & 3.0 & 15 & 3.2 & 23 & 4.9 & 24 & 5.2 & 29 & 6.2 \\
\hline Gambiae AgamP4* & 26 & 5.9 & 12 & 2.7 & 27 & 2.7 & 15 & 3.4 & 23 & 5.2 & 23 & 5.2 & 25 & 5.7 \\
\hline Gambiae Agams & 18 & 4.6 & 11 & 2.8 & 26 & 2.8 & 16 & 4.1 & 17 & 4.4 & 22 & 5.7 & 25 & 6.4 \\
\hline
\end{tabular}


Table 3 tRNA genes identified in 19 anopheline species (Continued)

\begin{tabular}{|c|c|c|c|c|c|c|c|c|c|c|c|c|c|c|}
\hline Quadrianulatus & 18 & 5.0 & 11 & 3.1 & 25 & 3.1 & 15 & 4.2 & 19 & 5.3 & 21 & 5.9 & 26 & 7.3 \\
\hline Sinensis & 22 & 6.1 & 9 & 2.5 & 29 & 2.5 & 13 & 3.6 & 19 & 5.3 & 22 & 6.1 & 27 & 7.5 \\
\hline Stephensi & 14 & 4.3 & 9 & 2.8 & 31 & 2.8 & 15 & 4.6 & 14 & 4.3 & 19 & 5.9 & 18 & 5.6 \\
\hline \multirow[t]{2}{*}{ Average aa per species } & 16.7 & 5.0 & 9.8 & 2.9 & 23.5 & 2.9 & 13.5 & 4.1 & 15.6 & 4.8 & 20.3 & 6.3 & 22.6 & 6.8 \\
\hline & \multicolumn{6}{|c|}{ - > Aromatic } & \multicolumn{4}{|c|}{ - > OH-containing } & \multicolumn{2}{|c|}{ - > Cyclic } & \multicolumn{2}{|c|}{ - > Seleno.-cont. } \\
\hline Anopheline species & Phe & $\%$ & Tyr & $\%$ & Trp & $\%$ & Ser & $\%$ & Thr & $\%$ & Pro & $\%$ & Sec & $\%$ \\
\hline Albimanus & 9 & 2.9 & 14 & 4.6 & 6 & 2.0 & 19 & 6.2 & 15 & 4.9 & 14 & 4.6 & 1 & 0.3 \\
\hline Arabiensis & 9 & 2.5 & 21 & 5.8 & 6 & 1.7 & 20 & 5.6 & 15 & 4.2 & 18 & 5.0 & 0 & \\
\hline Atroparvus & 9 & 2.7 & 17 & 5.0 & 6 & 1.8 & 18 & 5.3 & 16 & 4.7 & 23 & 6.8 & 1 & 0.3 \\
\hline Christyi & 9 & 3.0 & 9 & 3.0 & 5 & 1.7 & 17 & 5.7 & 15 & 5.0 & 15 & 5.0 & 0 & \\
\hline Coluzzii & 9 & 2.4 & 24 & 6.3 & 6 & 1.6 & 21 & 5.5 & 15 & 4.0 & 25 & 6.6 & 0 & \\
\hline Culicifacies & 9 & 3.1 & 11 & 3.8 & 5 & 1.7 & 18 & 6.3 & 16 & 5.6 & 13 & 4.5 & 2 & 0.7 \\
\hline Darlingi & 8 & 3.5 & 16 & 7.0 & 6 & 2.6 & 12 & 5.3 & 9 & 3.9 & 13 & 5.7 & 1 & 0.4 \\
\hline Dirus & 11 & 3.2 & 18 & 5.2 & 6 & 1.7 & 19 & 5.5 & 16 & 4.6 & 18 & 5.2 & 1 & 0.3 \\
\hline Epiroticus & 9 & 2.8 & 19 & 5.9 & 5 & 1.6 & 18 & 5.6 & 15 & 4.7 & 17 & 5.3 & 0 & \\
\hline Farauti & 11 & 3.1 & 21 & 5.9 & 6 & 1.7 & 21 & 5.9 & 17 & 4.8 & 18 & 5.1 & 3 & 0.8 \\
\hline Funestus & 9 & 3.1 & 17 & 5.9 & 5 & 1.7 & 17 & 5.9 & 15 & 5.2 & 15 & 5.2 & 0 & \\
\hline Maculatus & 2 & 1.6 & 6 & 4.8 & 2 & 1.6 & 8 & 6.3 & 10 & 7.9 & 3 & 2.4 & 1 & 0.8 \\
\hline Melas & 9 & 2.6 & 20 & 5.7 & 6 & 1.7 & 20 & 5.7 & 17 & 4.9 & 17 & 4.9 & 0 & \\
\hline Merus & 9 & 2.6 & 22 & 6.3 & 6 & 1.7 & 19 & 5.4 & 15 & 4.3 & 18 & 5.1 & & \\
\hline Minimus & 9 & 2.9 & 14 & 4.5 & 5 & 1.6 & 16 & 5.1 & 15 & 4.8 & 17 & 5.4 & 0 & \\
\hline Gambiae AgamP4 & 13 & 2.8 & 23 & 4.9 & 8 & 1.7 & 23 & 4.9 & 15 & 3.2 & 32 & 6.9 & 1 & 0.2 \\
\hline Gambiae AgamP4* & 9 & 2.0 & 22 & 5.0 & 7 & 1.6 & 22 & 5.0 & 15 & 3.4 & 32 & 7.3 & 0 & \\
\hline Gambiae Agams & 9 & 2.3 & 25 & 6.4 & 7 & 1.8 & 21 & 5.4 & 15 & 3.9 & 27 & 6.9 & 0 & \\
\hline Quadrianulatus & 9 & 2.5 & 24 & 6.7 & 6 & 1.7 & 19 & 5.3 & 16 & 4.5 & 19 & 5.3 & 0 & \\
\hline Sinensis & 9 & 2.5 & 21 & 5.8 & 6 & 1.7 & 18 & 5.0 & 15 & 4.2 & 17 & 4.7 & 0 & \\
\hline Stephensi & 10 & 3.1 & 17 & 5.2 & 5 & 1.5 & 19 & 5.9 & 14 & 4.3 & 23 & 7.1 & 2 & 0.6 \\
\hline Average aa per species & 9.0 & 2.7 & 18.1 & 5.4 & 5.7 & 1.7 & 18.3 & 5.6 & 14.8 & 4.6 & 18.8 & 5.5 & 0.7 & 0.5 \\
\hline
\end{tabular}

The columns under the amino acid name show the number of tRNA isoacceptor genes determined for each amino acid indicated, while neighboring columns show the respective percentage of the total number of tRNA genes for that isoacceptor in that particular species. Cells with characters in bold/italic font show numbers that differ significantly for that particular tRNA from the other species. The taxon indicated as gambiae AgamP4* refers to the numbers obtained by Behura and Severson (Behura and Severson 2011; see Results). The four additional columns at the right-hand side of the first part of the table show additional data such as (from left to right) the number of pseudogenes detected (PG), the total number of tRNA genes in the species ( $\Sigma$ ), the genome size based on the assemblies $(\mathrm{Mb})$ and the number of tRNA genes per $\mathrm{Mb}$ of genomic sequence $(\mathrm{F})$.

or the name of the ortholog found through similarity searches. Interestingly, six miRNAs were found to be encoded by the genomes of all taxa analyzed. These were mir-10, mir-100, mir-1000, mir-315, mir-8 and mir-iab-4. Of those, mir-10 and mir-100 have been found in a large variety of species [87], while the remaining four have been found, with one exception, only in insects. Most of these miRNA species influence developmental pathways. Mir-iab-4 and mir-10, for example, are involved in the regulation of Hox genes, miR-100 has a role in apoptotic pathways, mir315 and mir- 8 are implicated in the Wingless (Wg) signaling pathway, the latter being also involved in the regulation of neurogenic signals and gliogenesis in Drosophila. When comparing the genomes of the members of the Anopheles gambiae species complex, we identified an additional 21 genes that were common to all species in the complex (let-7, mir-1, mir-125, mir-1891, mir-190, mir-219, mir-252, mir-263a, mir-263b, mir-2765, mir-282, mir-283, mir-286, mir-305, mir-34, mir-7, mir-927, mir-929, mir-932, mir-993, mir-9b).

Table 4 also shows that, in most cases, the miRNAs identified have been annotated as such in Rfam. A significant number of putative miRNAs identified here, though, remained anonymous (percentage of the anonymous miRNAs varies from $0 \%-48 \%$ depending on the species). Those miRNAs have been analyzed further and we found that the majority has, been annotated as miRNAs in RefSeq (again percentages varying from 67\% - 100\%). The remaining ones are simply classified as ncRNAs in RefSeq [88] without further details; we believe these to be 
Table 4 miRNA genes discovered

\begin{tabular}{|c|c|c|c|c|c|c|}
\hline & $\begin{array}{l}\text { miRNA } \\
\text { predictions - this } \\
\text { study }\end{array}$ & $\begin{array}{l}\text { Previously } \\
\text { annotated as } \\
\text { miRNA (miRBAse) }\end{array}$ & $\begin{array}{l}\text { Putative } \\
\text { new miRNAs: } \\
\text { Refseq ncRNA }\end{array}$ & $\begin{array}{l}\text { miRNA - already } \\
\text { in VB }\end{array}$ & $\begin{array}{l}\text { Common } \\
\text { genes - this } \\
\text { study/VB }\end{array}$ & $\begin{array}{l}\% \text { Common -this } \\
\text { study/VB }\end{array}$ \\
\hline Albimanus & 96 & 89 & 7 & 67 & 53 & 55.2 \\
\hline Arabiensis & 95 & 88 & 7 & 83 & 58 & 61.1 \\
\hline Atroparvus & 96 & 93 & 3 & 53 & 38 & 39.6 \\
\hline Christyi & 93 & 85 & 8 & 69 & 60 & 64.5 \\
\hline Coluzzii & 43 & 43 & 0 & 0 & 0 & 0 \\
\hline Culicifacies & 71 & 71 & 0 & 75 & 39 & 54.9 \\
\hline Darlingi & 55 & 55 & 0 & 57 & 18 & 32.7 \\
\hline Dirus & 110 & 110 & 0 & 61 & 37 & 33.6 \\
\hline Epiroticus & 85 & 79 & 6 & 73 & 53 & 62.4 \\
\hline Farauti & 108 & 99 & 9 & 62 & 48 & 44.4 \\
\hline Funestus & 113 & 104 & 9 & 66 & 48 & 42.5 \\
\hline Gambiae-PEST & 63 & 58 & 5 & 172 & 21 & 33.3 \\
\hline Gambiae-S & 61 & 61 & 0 & 0 & 0 & 0 \\
\hline Maculatus & 40 & 40 & 0 & 53 & 35 & 87.5 \\
\hline Melas & 65 & 65 & 0 & 82 & 38 & 58.5 \\
\hline Merus & 118 & 107 & 11 & 86 & 58 & 49.2 \\
\hline Minimus & 48 & 48 & 0 & 65 & 35 & 72.9 \\
\hline Quadriannulatus & 97 & 92 & 5 & 75 & 55 & 56.7 \\
\hline Sinensis & 115 & 105 & 10 & 76 & 50 & 43.5 \\
\hline Stephensi & 111 & 107 & 4 & 65 & 45 & 40.5 \\
\hline
\end{tabular}

The table lists the number of genes discovered and compares them to the list of miRNA genes annotated in miRBase, VB or the RFAM and RefSeq databases.

miRNAs that are identified as such here for the first time. Their percentage is always smaller that $10 \%$ of the miRNAs accepted in our final set. Driven by the fact that more miRNAs are present in the very recent RefSeq database, we re-annotated our RNAz results versus RefSeq. In six genomes (A. culicifacies, A.dirus, A. epiroticus, A. funestus, A. merus and A. stephensi) an additional putative miRNA gene similar to mir-2796 was identified. In cases in which VectorBase listed annotated miRNA genes, between 32 and $73 \%$ of the ones identified in the present study were in common. In contrast, between $12.5 \%$ and $67 \%$ of the genes that we predict were not picked up by the VectorBase pipeline.

While writing this manuscript a study describing a transcriptome-wide analysis of miRNA expression in $A$. gambiae was published reporting previously unidentified miRNAs [85]. Although an overlap exists between "our" presumed miRNA genes and the ones reported there, there is a high inconsistency as far as total numbers of miRNAs identified in A. gambiae are concerned (see also miRNAs present in VectorBase). We stress that we have used a conservative approach in naming miRNA genes since we only made use of a bioinformatics pipeline. In all other anopheline species, the numbers of genes identified are about "equal", still the actual identity overlap between them is, again, $\sim 50 \%$. This is clearly a result of the fact that pure computational approaches were used. Which values are "more correct" can only be evaluated in the future when users look at the data and determine by themselves, especially performing "wet experiments".

\section{The snRNA genes}

Without attempting a systematic approach, a by-product of searching for miRNA genes through the usage of RNAz was the identification of a series of additional non-coding RNA genes. The results are summarized in Table 5 and shown in Additional file 6. Genes coding for U1 spliceosomal RNA [89] were found most often; only in $A$. minimus was no gene identified. In addition to U1 RNA genes, genes for another 6 classes were discovered, namely for U4, U4atac, U5, U6atac, U11 and U12 RNAs (see [90]).

\section{Conclusions}

This report presents a comprehensive search and scan of NGS genomic alignments to identify and annotate several families of non-protein encoding RNA genes. This work was an integral part of the project carried out by the "Anopheles Genomes Cluster Consortium" producing, using NGS, assemblied genomes for a collection of 
Table 5 snRNA genes in anophelines

\begin{tabular}{|c|c|c|c|c|c|c|c|}
\hline & U1 & U4 & U4atac & U5 & U6atac & U11 & U12 \\
\hline Albimanus & 3 & 2 & & & & & \\
\hline Arabiensis & 5 & 1 & & 1 & & & 1 \\
\hline Atroparvus & 6 & 2 & & 2 & & 1 & \\
\hline Christyi & 2 & 1 & & & & 1 & 1 \\
\hline Culicifacies & 1 & 1 & & & & 1 & 1 \\
\hline Darlingi & 4 & & 1 & & & 1 & \\
\hline Dirus & 4 & 1 & 1 & & & & \\
\hline Epiroticus & 5 & & & & 1 & & \\
\hline Farauti & 4 & 2 & & & & & \\
\hline Funestus & 2 & 1 & & & & 1 & 1 \\
\hline Gambiae PEST & 2 & 1 & & & 1 & & \\
\hline Gambiae S & 3 & 1 & 1 & & & 1 & \\
\hline Maculatus & 1 & & & & & & \\
\hline Melas & 2 & & & & & & \\
\hline Merus & 4 & 1 & & & & & 1 \\
\hline Minimus & & 1 & & & & & \\
\hline Quadriannulatus & 3 & 1 & & & & & 1 \\
\hline Sinensis & 4 & 1 & & & & 1 & \\
\hline Stephensi & 1 & 1 & & & & 1 & \\
\hline
\end{tabular}

The Table lists the number and species of snRNAs identified in 19 anopheline taxa examined.

19 anopheline species. Of all ncRNA families, we concentrated on those presented here, for different reasons, the most crucial of which being the possibility to obtain conclusive answers exclusively through the usage of computational methods. Thus, families such as Piwiinteracting RNAs [91] that, additionally, require a PCR approach for their identification were not part of the present study.

We succeeded in identifying and producing a preliminary computational analysis of a variety of genes. It is obvious, given the fact that only computational methods were used, that we chose a rather conservative approach in our analysis. Although this decision may lead to a relative lack of information, we think that this will be more helpful to the Anopheles research community; it is provided with a repertoire of genes that can function as molecular tools in a series of experimental designs, most prominently, but clearly not exclusively, for evolutionary studies at different levels. In addition to that, the study provided answers to some questions that had remained unanswered for several years. For example, it was clearly established that the presumed contiguous structure of the $5.8 \mathrm{~S}$ rRNA in anophelines is a fact, in contrast to what is true for other insects, including D. melanogaster.

This study also demonstrated some weak points that are linked to the usage of NGS approaches in WGS of genomes. These pitfalls mostly affect the study of highly repeated segments such as, in our case, the ribosomal genes. Not only did we find that, in many of the genes examined, rDNA segments are entirely missing from the assemblies, we also noticed the presence of several mistakes in these assemblies. This remains a problem that will have to be solved, in the future, through the acquisition of longer sequence reads [92] or the development of enhanced software. Nevertheless, it is clear that significant conclusions can already be drawn, especially when one considers the availability of RNAseq experiments that accompany the whole genome sequencing. In our case, the availability of special RNAseq sets (e.g. designed for short RNA sequences), would have greatly improved several aspects of this study.

In conclusion we can say that the approach chosen by the "Anopheles Genomes Cluster Consortium" can be called successful. Joining a number of expert groups in the analysis of a large set of anopheline species to analyze the results obtained from the NGS-based genome analysis can clearly lead to the acquisition of a wealth of biological data, even considering some drawbacks due to the technologies available today.

\section{Availability of supporting data}

The data sets supporting the results of this article are included within the article and its additional files. All the genomic assemblies and sequences used in this analysis are available at VectorBase (http://www.vectorbase.org). Consensus sequences described, and genes identified here have been submitted to VectorBase for inclusion in the corresponding species pages. Phylogenetic data have been submitted at TreeBASE (http://purl.org/phylo/treebase/ phylows/study/TB2:S16748).

\section{Additional files}

Additional file 1: List of the rDNA segments species used in the phylogenetic analyses. The numbers indicate the corresponding segment in Table 1 or, in the case of D. melanogaster, the sequence stored with the accession number M21017. The accession numbers for the mitochondrial Cytochrome c oxidase subunit I (COI) and the mitochondrial $16 \mathrm{~S}$ rDNA (16S) refer to the corresponding accession numbers in the Genbank/EMBL databases. (-: not used).

Additional file 2: rDNA repeat sequences for the anophelines listed in Table 2. This txt file is essentially a FASTA-formatted file that contains all sequences determined and listed in Table 1. The sequences are listed alphabetically by species name. Where a sequence is missing, a dash $(-)$ indicates this and, if known, the approximate length of the segment missing is indicated in the sequence description. Otherwise, the coordinates for each rDNA segment are given after the name of the segment ( - is always counted as 1 nucleotide in the calculation of lengths in the file).

Additional file 3: snoRNA genes identified in the anopheline genomes. This txt file is essentially a FASTA-formatted file that contains all sequences determined and listed in Table 2. The sequences are listed alphabetically following the names of the taxa. The coordinates of the scaffold in which the sequence was detected iare indicated in the description line, followed by a short description of the computed stem 
structure (see Table 2 and Results) as well as, finally, the target sequence used.

\section{Additional file 4: tRNA genes identified in the anopheline} genomes. This txt file is essentially a FASTA-formatted file that contains all sequences determined and listed in Table 3. The sequences are listed alphabetically following the names of the taxa. The coordinates of the scaffold in which the sequence was detected are indicated in the description line, followed by a short description of the tRNA encoded.

\section{Additional file 5: miRNA genes identified in the anopheline}

genomes. This txt file is essentially a FASTA-formatted file that contains all sequences determined and listed in Table 4. The sequences are listed alphabetically following the names of the taxa. The coordinates of the scaffold in which the sequence was detected as well as the direction of transcription are indicated in the header line. The header also contains, when available, the coordinates and the sequence of the mature miRNA.

Additional file 6: snRNA genes identified. The table lists the species, the scaffold coordinates and the kind of snRNA identified.

\section{Competing interests}

The authors declare that they have no competing interests.

\section{Authors' contributions}

$V D, E D, E D, N P, J A, D L, C L$ and $P T$ generated, analyzed the data and drafted the manuscript. All authors edited and approved the final manuscript. ED and VD contributed equally to the analysis and should both be considered as first authors.

\section{Acknowledgments}

We would like to thank Drs. Nora Besansky, Dan Neafsey and Robert Waterhouse for the excellent collaboration over the course of this investigation. We are also indebted to Dr George Dimitrakakis (University of Crete,Center of Communication \& Networking) for assistance with the use of the HPC cluster.

This work was supported by the National Institutes of Health/National Institute for Allergy and Infectious Diseases [grant number HHSN272200900039C; VectorBase], by the Infravec program (FP7) of the European Commission [Grant Agreement 228421] and by i-Move fellowships (Marie Curie Action, FP7) to $\mathrm{VD}$ and $\mathrm{CL}$.

This paper is dedicated to the memory of Maria Topali.

\section{Author details}

${ }^{1}$ Centre for Functional Genomics, University of Perugia, Perugia, Italy. ${ }^{2}$ Institute of Molecular Biology and Biotechnology, FORTH, Heraklion, Greece. ${ }^{3}$ Department of Biology, University of Crete, Heraklion, Greece. ${ }^{4}$ Natural History Museum of Crete, University of Crete, Heraklion, Greece. ${ }^{5}$ European Bioinformatics Institute, Hinxton, UK.

Received: 18 August 2014 Accepted: 19 November 2014 Published: 28 November 2014

\section{References}

1. Beaty BJ, Prager DJ, James AA, Jacobs-Lorena M, Miller LH, Law JH, Collins $\mathrm{FH}$, Kafatos FC: From Tucson to genomics and transgenics: the vector biology network and the emergence of modern vector biology. PLOS Negl Trop Dis 2009, 3:e343.

2. Holt RA, Subramanian GM, Halpern A, Sutton GG, Charlab R, Nusskern DR, Wincker P, Clark AG, Ribeiro JM, Wides R, Salzberg SL, Loftus B, Yandell M, Majoros WH, Rusch DB, Lai Z, Kraft CL, Abril JF, Anthouard V, Arensburger P, Atkinson PW, Baden H, de Berardinis V, Baldwin D, Benes V, Biedler J, Blass C, Bolanos R, Boscus D, Barnstead M, et al: The genome sequence of the malaria mosquito Anopheles gambiae. Science 2002, 298:129-149.

3. Adams MD, Celniker SE, Holt RA, Evans CA, Gocayne JD, Amanatides PG, Scherer SE, Li PW, Hoskins RA, Galle RF, George RA, Lewis SE, Richards S, Ashburner M, Henderson SN, Sutton GG, Wortman JR, Yandell MD, Zhang Q Chen LX, Brandon RC, Rogers YH, Blazej RG, Champe M, Pfeiffer BD, Wan KH, Doyle C, Baxter EG, Helt G, Nelson CR, et al: The genome sequence of Drosophila melanogaster. Science 2000, 287:2185-2195.

4. Neafsey DE, Christophides GK, Collins FH, Emrich SJ, Fontaine MF, Gelbart W, Hahn MW, Howell PI, Kafatos FC, Lawson D, Muskavitch MA, Waterhouse
RM, Williams LJ, Besansky NJ: The Evolution of the Anopheles 16 Genomes Project. G3 (Bethesda) 2013, 3:1191-1194.

5. Brenner S, Jacob F, Meselson M: An unstable intermediate carrying information from genes to ribosomes for protein synthesis. Nature 1961, 190:576-581.

6. Gros F, Hiatt H, Gilbert W, Kurland CG, Risebrough RW, Watson JD: Unstable ribonucleic acid revealed by pulse labeling of Escherichia coli. Nature 1961, 190:581-585.

7. Aronson Al, McCarthy BJ: Studies of E. coli ribosomal RNA and its degradation products. Biophys J 1961, 1:215-226.

8. Crick FH: On protein synthesis. Symp Soc Exp Biol 1958, 12:138-163

9. Crick FH: Central dogma of molecular biology. Nature 1970, 227:561-563.

10. Eddy SR: Non-coding RNA genes and the modern RNA world. Nat Rev Genet 2001, 2:919-929.

11. Neafsey DE, Waterhouse RM, Abai MR, Aganezov SS, Alekseyev MA, Allen JE, Amon J, Arcà B, Arensburger P, Artemov G, Assour LA, Basseri H, Berlin A Birren BW, Blandin SA, Brockman Al, Burkot TR, Burt A, Chan CS, Chauve C, Chiu JC, Christensen M, Costantini C, Davidson VLM, Deligianni E, Dottorini T, Dritsou V, Gabriel SB, Guelbeogo WM, Hall AB, et al: Highly evolvable malaria vectors: the genomes of 16 Anopheles mosquitoes. Science 2014 Published online 27 November 2014 [DOI:10.1126/science.1258522].

12. Megy K, Emrich SJ, Lawson D, Campbell D, Dialynas E, Hughes DS, Koscielny G, Louis C, Maccallum RM, Redmond SN, Sheehan A, Topalis P, Wilson D: VectorBase: improvements to a bioinformatics resource for invertebrate vector genomics. Nucleic Acids Res 2012, 40:D729-D734.

13. Altschul SF, Madden TL, Schäffer AA, Zhang J, Zhang Z, Miller W, Lipman DJ: Gapped BLAST and PSI-BLAST: a new generation of protein database search programs. Nucleic Acids Res 1997, 25:3389-3402.

14. Tautz D, Hancock JM, Webb DA, Tautz C, Dover GA: Complete sequences of the rRNA genes of Drosophila melanogaster. Mol Biol Evol 1988, 5:366-376.

15. Wheeler DL, Barrett T, Benson DA, Bryant SH, Canese K, Chetvernin V, Church DM, Dicuccio M, Edgar R, Federhen S, Feolo M, Geer LY, Helmberg W, Kapustin Y, Khovayko O, Landsman D, Lipman DJ, Madden TL, Maglott DR, Miller V, Ostell J, Pruitt KD, Schuler GD, Shumway M, Sequeira E, Sherry ST, Sirotkin K, Souvorov A, Starchenko G, Tatusov RL, et al: Database resources of the National Center for Biotechnology Information. Nucleic Acids Res 2008, 36:D13-D21.

16. Artavanis-Tsakonas S, Schedl P, Tschudi C, Pirrotta V, Steward R, Gehring WJ: The 5 S genes of Drosophila melanogaster. Cell 1977, 12:1057-1067.

17. Katoh K, Misawa K, Kuma K, Miyata T: MAFFT: a novel method for rapid multiple sequence alignment based on fast Fourier transform. Nucleic Acids Res 2002, 30:3059-3066.

18. Darriba D, Taboada GL, Doallo R, Posada D: ModelTest 2: more models, new heuristics and parallel computing. Nat Methods 2012, 2012(9):772.

19. Yang Z: Computational Molecular Evolution. Oxford \& New York: Oxford University Press; 2006.

20. Ronquist F, Teslenko M, van der Mark P, Ayres DL, Darling A, Hohna S, Larget B, Liu L, Suchard MA, Huelsenbeck JP: MrBayes 3.2: efficient bayesian phylogenetic inference and model choice across a large model space. Syst Biol 2012, 61:539-542.

21. Stamatakis A: RAxML-VI-HPC: Maximum likelihood-based phylogenetic analyses with thousands of taxa and mixed models. Bioinformatics 2006, 22:2688-2690.

22. Rambaut A, Suchard MA, Xie W, Drummond AJ: MCMC Trace Analysis Tool. Version v1.6.0. http://beast.bio.ed.ac.uk/Tracer 2013, accessed 25 July 2014.

23. Robinson D, Foulds LR: Comparison of phylogenetic trees. Math Biosci 1981, 53:131-147.

24. Tamura K, Stecher G, Peterson D, Filipski A, Kumar S: MEGA6: molecular evolutionary genetics analysis version 6.0. Mol Biol Evol 2013, 30:2725-2729

25. Lowe TM, Eddy S: tRNAScan-SE: a program for improved detection of transfer RNA genes in genomic sequence. Nucleic Acids Res 1997, 25:955-964.

26. Gruber AR, Findeiß S, Washietl S, Hofacker IL, Stadler PF: RNAz 2.0: improved noncoding RNA detection. Pac Symp Biocomput 2010, 15:69-79.

27. Griffiths-Jones S, Bateman A, Marshall M, Khanna A, Eddy SR: Rfam: an RNA family database. Nucleic Acids Res 2003, 31:439-441.

28. Burge SW, Daub J, Eberhardt R, Tate J, Barquist L, Nawrocki EP, Eddy SR, Gardner PP, Bateman A: Rfam 11.0: 10 years of RNA families. Nucleic Acids Res 2013, 41(Database issue):D226-D232. 
29. Kadri S, Hinman V, Benos PV: HHMMiR: efficient de novo prediction of microRNAs using hierarchical hidden Markov models. BMC Bioinformatics 2009, 10(Suppl 1):S35.

30. Wu Y, Wei B, Liu H, Li T, Rayner S: MiRPara: a SVM-based software tool for prediction of most probable microRNA coding regions in genome scale sequences. BMC Bioinformatics 2011, 12:107.

31. Griffiths-Jones S, Grocock RJ, van Dongen S, Bateman A, Enright AJ: miRBase: microRNA sequences, targets and gene nomenclature. Nucleic Acids Res 2006, 34(Database issue):D140-D144.

32. Kozomara A, Griffiths-Jones S: miRBase: annotating high confidence microRNAs using deep sequencing data. Nucleic Acids Res 2014, 42(Database issue):D68-D73.

33. Lowe TM, Eddy S: 1999A computational screen for methylation guide snoRNAs in yeast. Science 1999, 283:1168-1171.

34. Hertel J, Hofacker IL, Stadler PF: SnoReport: computational identification of snoRNAs with unknown targets. Bioinformatics 2008, 15:158-164.

35. Glover DM, Hogness DS: A novel arrangement of the $18 \mathrm{~S}$ and $28 \mathrm{~S}$ sequences in a repeating unit of Drosophila melanogaster rDNA. Cell 1977, 10:167-176.

36. White RL, Hogness DS: R loop mapping of the $18 \mathrm{~S}$ and $28 \mathrm{~S}$ sequences in the long and short repeating units of Drosophila melanogaster rDNA Cell 1977, 10:177-192.

37. Glover DM: Cloned segment of Drosophila melanogaster rDNA containing new types of sequence insertion. Proc Natl Acad Sci U S A 1977, 74:4932-4936.

38. Jakubczak JL, Burke WD, Eickbush TH: Retrotransposable elements RI and R2 interrupt the rRNA genes of most insects. Proc Natl Acad Sci U S A 1991, 88:3295-3299.

39. Besansky NJ, Paskewitz SM, Hamm DM, Collins FH: Distinct families of site-specific retrotransposons occupy identical positions in the rRNA genes of Anopheles gambiae. Mol Cell Biol 1992, 12:5102-5110.

40. Collins FH, Mendez MA, Rasmussen MO, Mehaffey PC, Besansky NJ, Finnerty $\mathrm{V}$ : A ribosomal RNA gene probe differentiates member species of the Anopheles gambiae complex. Am J Trop Med Hyg 1987, 37:37-41.

41. Wilkins $E E$, Howell PI, Benedict MQ: $X$ and $Y$ chromosome inheritance and mixtures of rDNA intergenic spacer regions in Anopheles gambiae. Insect Mol Biol 2007, 16:735-741.

42. Bargues MD, Latorre JM, Morchon R, Simon F, Escosa R, Aranda C, Sainz S, Fuentes MV, Mas-Coma S: rDNA sequences of Anopheles species from the Iberian Peninsula and an evaluation of the 18S rRNA gene as phylogenetic marker in anophelinae. J Med Entomol 2006, 43:508-517.

43. Sallum MAM, Schultz TR, Foster PG, Aronstein K, Wirtz RA, Wilkerson RC: Phylogeny of Anophelinae (Diptera: Culicidae) based on nuclear ribosomal and mitochondrial DNA sequences. Syst Entomol 2002, 27:361-382.

44. Beebe NW, Cooper RD, Morrison DA, Ellis JT: A phylogenetic study of the Anopheles punctulatus group of malaria vectors comparing rDNA sequence alignments derived from the mitochondrial and nuclear small ribosomal subunits. Mol Phylogenet Evol 2000, 17:430-43618.

45. Besansky NJ, Powell JR, Caccone A, Hamm DM, Scott JA, Collins FH: Molecular Phylogeny of the Anopheles gambiae Complex Suggests Genetic Introgression between Principal Malaria Vectors. PNAS 1994 91:6885-6888

46. Bower JE, Cooper RD, Beebe NW: Internal repetition and intraindividua variation in the rDNA ITS1 of the anopheles punctulatus group (Diptera: Culicidae): multiple units and rates of turnover. J Mol Evol 2009, 68:66-79.

47. Schultz J, Wolf M: ITS2 sequence-structure analysis in phylogenetics: a how-to manual for molecular systematics. Mol Phylogenet Evol 2009, 52:520-523.

48. Shimada T: Distribution of split $5.8 \mathrm{~s}$ ribosomal RNA in Diptera. Insect Mol Biol 1992, 1:45-48.

49. Jordan BR, Glover DM: $5.8 \mathrm{~S}$ and $2 \mathrm{~S}$ rDNA is located in the 'transcribed spacer' region between the $18 \mathrm{~S}$ and $26 \mathrm{~S}$ rRNA genes in Drosophila melanogaster. FEBS Lett 1977, 78:271-274.

50. Lee J, Traut R: Proximity of 5.8S RNA-binding proteins and A-site proteins in yeast ribosomes inferred from cross-linking. J Biol Chem 1984, 259:9971-9974.

51. Miller BR, Crabtree MB, Savage HM: Phylogenetic relationships of the Culicomorpha inferred from $18 \mathrm{~s}$ and $5.8 \mathrm{~s}$ ribosomal DNA sequences (Diptera: Nematocera). Insect Mol Biol 1997, 6:105-114

52. Collins FH, Paskewitz SM: A review of the use of ribosomal DNA (rDNA) to differentiate among cryptic Anopheles species. Insect Mol Biol 1996, 5:1-9.
53. Besansky NJ: Complexities in the analysis of cryptic taxa within the genus Anopheles. Parassitologia 1999, 41:97-100.

54. Scott JA, Brogdon WG, Collins FH: Identification of single specimens of the Anopheles gambiae complex by the polymerase chain reaction. Am J Trop Med Hyg 1993, 49:520-529.

55. Favia G, Lanfrancotti A, Spanos L, Sidén-Kiamos I, Louis C: Molecular characterization of ribosomal DNA polymorphisms discriminating among chromosomal forms of Anopheles gambiae s.s. Insect Mol Biol 2001, 10:19-23.

56. Joshi D, Park MH, Saeung A, Choochote W, Min GS: Multiplex assay to identify Korean vectors of malaria. Mol Ecol Resour 2010, 10:748-750.

57. Spirin AS: Ribosomes. New York: Kluwer; 1999.

58. Rubin GM, Hogness DS: Effect of heat shock on the synthesis of low molecular weight RNAs in drosophilia: accumulation of a novel form of 5S RNA. Cell 1975, 6:207-213.

59. Jacq B, Jourdan R, Jordan BR: Structure and processing of precursor $5 \mathrm{~S}$ RNA in Drosophila melanogaster. J Mol Biol 1977, 117:785-795.

60. Tschudi C, Pirrotta V: Sequence and heterogeneity in the 5S RNA gene cluster of Drosophila melanogaster. Nucleic Acids Res 1980, 8:441-451.

61. Gillespie JJ, Johnston JS, Cannone JJ, Gutell RR: Characteristics of the nuclear (18S, 5.8S, 28S and 5S) and mitochondrial (12S and 16S) rRNA genes of Apis mellifera (Insecta: Hymenoptera): structure, organization, and retrotransposable elements. Insect Mol Biol 2006, 15:657-686.

62. Louis C, Schedl P, Samal B, Worcel A: Chromatin structure of the 5 S genes in Drosophila melanogaster. Cell 1980, 22:387-392.

63. Wolffe AP: RNA polymerase III transcription. Curr Opin Cell Biol 1991, 3:461-466.

64. Preiser PR, Levinger LF: In vitro processing of Drosophila melanogaster $5 \mathrm{~S}$ ribosomal RNA. $3^{\prime}$ end effects and requirement for internal domains of mature 5 S RNA. J Biol Chem 1991, 266:7509-7516.

65. Preiser PR, Levinger LF: Drosophila 5 S RNA processing requires the $1-118$ base pair and additional sequence proximal to the processing site. $J \mathrm{Biol}$ Chem 1991, 266:23602-23605.

66. Preiser PR, Vasisht V, Birk A, Levinger LF: Poly(U)-binding protein inhibits Drosophila pre-5 S RNA 3'-exonuclease digestion. J Biol Chem 1993, 268:11553-11557.

67. Gottesfeld JM, Bloomer LS: Nonrandom alignment of nucleosomes on $5 S$ RNA genes of X. laevis. Cell 1980, 21:751-760.

68. Lui L, Lowe T: Small nucleolar RNAs and RNA-guided post-transcriptional modification. Essays Biochem 2013, 54:53-77.

69. Smith CM, Steitz JA: Sno storm in the nucleolus: new roles for myriad small RNPs. Cell 1997, 89:669-672.

70. Schattner P, Decatur WA, Davis CA, Ares M Jr, Fournier MJ, Lowe TM: Genome-wide searching for pseudouridylation guide snoRNAs: analysis of the Saccharomyces cerevisiae genome. Nucleic Acids Res 2004, 32:4281-4296

71. St. Pierre SE, Ponting L, Stefancsik R, McQuilton P, The FlyBase Consortium: FlyBase 102 - advanced approaches to interrogating FlyBase. Nucleic Acids Res 2014, 42(D1):D780-D788.

72. Long EO, Dawid IB: Repeated genes in eukaryotes. Ann Rev Biochem 1980, 49:727-764

73. Holley RW, Apgar J, Everett GA, Madison JT, Marquisee M, Merrill SH, Penswick JR, Zamir A: Structure of a ribonucleic acid. Science 1965 147:1462-1465.

74. Kubli E: The structure and function of tRNA genes of higher eukaryotes. Experientia 1981, 37:1-9.

75. Kubli E: The Genetics of Transfer RNA in Drosophila. Adv Genet 1982, 21:123-172.

76. Behura SK, Severson DW: Coadaptation of isoacceptor tRNA genes and codon usage bias for translation efficiency in Aedes aegypti and Anopheles gambiae. Insect Mol Biol 2011, 20:177-187.

77. Coetzee M, Hunt RH, Wilkerson R, Della Torre A, Coulibaly MB, Besansky NJ: Anopheles coluzzii and Anopheles amharicus, new members of the Anopheles gambiae complex. Zootaxa 2013, 3619:246-274.

78. Pombi M, Stump AD, Della Torre A, Besansky NJ: Variation in recombination rate across the $X$ chromosome of Anopheles gambiae. Am J Trop Med Hyg 2006, 75:901-903.

79. Bartel D: MicroRNAs: genomics, biogenesis, mechanism, and function. Cell 2004, 116:281-297.

80. Kim V, Han J, Siomi M: Biogenesis of small RNAs in animals. Nat Rev Mol Cell Biol 2009, 10:126-139. 
81. Bartel DP: MicroRNAs: target recognition and regulatory functions. Cell 2009, 136:215-233.

82. Mead E, Tu Z: Cloning, characterization, and expression of microRNAs from the Asian malaria mosquito, Anopheles stephensi. BMC Genomics 2008, 9:244.

83. Li S, Mead EA, Liang S, Tu Z: Direct sequencing and expression analysis of a large number of miRNAs in Aedes aegypti and a multi-species survey of novel mosquito miRNAs. BMC Genomics 2009, 10:581.

84. Skalsky RL, Vanlandingham DL, Scholle F, Higgs S, Cullen BR: Identification of microRNAs expressed in two mosquito vectors, Aedes albopictus and Culex quinquefasciatus. BMC Genomics 2010, 11:119.

85. Biryukova I, Ye T, Levashina E: Transcriptome-wide analysis of microRNA expression in the malaria mosquito Anopheles gambiae. BMC Genomics 2014, 15:557.

86. Winter F, Edaye $S$, Hüttenhofer A, Brunel C: Anopheles gambiae miRNAs as actors of defence reaction against Plasmodium invasion. Nucleic Acids Res 2007, 35:6953-6962

87. Griffiths-Jones S, Hui JH, Marco A, Ronshaugen M: MicroRNA evolution by arm switching. EMBO Rep 2011, 12:172-177.

88. Pruitt KD, Brown GR, Hiatt SM, Thibaud-Nissen F, Astashyn A, Ermolaeva O, Farrell CM, Hart J, Landrum MJ, McGarvey KM, Murphy MR, O'Leary NA, Pujar S, Rajput B, Rangwala SH, Riddick LD, Shkeda A, Sun H, Tamez P, Tully RE, Wallin C, Webb D, Weber J, Wu W, DiCuccio M, Kitts P, Maglott DR, Murphy TD, Ostell JM: RefSeq: an update on mammalian reference sequences. Nucleic Acids Res 2013, 42:D756-D763.

89. Valadkhan S: snRNAs as the catalysts of pre-mRNA splicing. Curr Opin Chem Biol 2005, 9:603-608.

90. Valadkhan S, Gunawardane LS: Role of small nuclear RNAs in eukaryotic gene expression. Essays Biochem 2013, 54:79-90.

91. Seto AG, Kingston RE, Lau NC: The coming of age for piwi proteins. Mol Cell 2007, 26:603-609.

92. Roberts RJ, Carneiro MO, Schatz MC: The advantages of SMRT sequencing. Genome Biol 2013, 14:405.

doi:10.1186/1471-2164-15-1038

Cite this article as: Dritsou et al: Non-coding RNA gene families in the genomes of anopheline mosquitoes. BMC Genomics 2014 15:1038.

\section{Submit your next manuscript to BioMed Central and take full advantage of:}

- Convenient online submission

- Thorough peer review

- No space constraints or color figure charges

- Immediate publication on acceptance

- Inclusion in PubMed, CAS, Scopus and Google Scholar

- Research which is freely available for redistribution 